\title{
Review \\ A Review on Precision Polishing Technology of Single-Crystal SiC
}

\author{
Gaoling Ma, Shujuan Li *, Feilong Liu *, Chen Zhang, Zhen Jia and Xincheng Yin (1)
}

Citation: Ma, G.; Li, S.; Liu, F.; Zhang, C.; Jia, Z.; Yin, X. A Review on Precision Polishing Technology of Single-Crystal SiC. Crystals 2022, 12, 101. https://doi.org/10.3390/ cryst12010101

Academic Editors: Mihaela Kusko, Florin Nastase and Evgeniy N. Mokhov

Received: 24 November 2021

Accepted: 10 January 2022

Published: 13 January 2022

Publisher's Note: MDPI stays neutral with regard to jurisdictional claims in published maps and institutional affiliations.

Copyright: (c) 2022 by the authors. Licensee MDPI, Basel, Switzerland. This article is an open access article distributed under the terms and conditions of the Creative Commons Attribution (CC BY) license (https:// creativecommons.org/licenses/by/ $4.0 /)$.
School of Mechanical and Precision Instrument Engineering, Xi'an University of Technology, Xi'an 710048, China; magaoling@stu.xaut.edu.cn (G.M.); 2200220061@stu.xaut.edu.cn (C.Z.); 1190210001@stu.xaut.edu.cn (Z.J.); yinxincheng@stu.xaut.edu.cn (X.Y.)

* Correspondence: shujuanli@xaut.edu.cn (S.L.); 105071@xaut.edu.cn (F.L.); Tel.: +86-29-82312806 (S.L.)

Abstract: Single-crystal $\mathrm{SiC}$ is a typical third-generation semiconductor power-device material because of its excellent electronic and thermal properties. An ultrasmooth surface with atomic surface roughness that is scratch free and subsurface damage (SSD) free is indispensable before its application. As the last process to reduce the surface roughness and remove surface defects, precision polishing of single-crystal $\mathrm{SiC}$ is essential. In this paper, precision polishing technologies for $4 \mathrm{H}-\mathrm{SiC}$ and $6 \mathrm{H}-\mathrm{SiC}$, which are the most commonly used polytypes of single-crystal $\mathrm{SiC}$, such as chemical mechanical polishing (CMP), photocatalytic chemical mechanical polishing (PCMP), plasma-assisted polishing (PAP), electrochemical mechanical polishing (ECMP), and catalyst-referred etching (CARE), were reviewed and compared with emphasis on the experimental setup, polishing mechanism, material removal rate (MRR), and surface roughness. An atomically smooth surface without SSD can be obtained by CMP, PCMP, PAP, and CARE for single-crystal SiC. However, their MRRs are meager, and the waste treatment after CMP is difficult and expensive. Moreover, PAP's operation is poor due to the complex polishing system, plasma generation, and irradiation devices. A high MRR can be achieved by ECMP. In addition, it is an environmentally friendly precision polishing process for single-crystal $\mathrm{SiC}$ since the neutral salt solution is generally used as the electrolyte in ECMP. However, the formation of the egglike protrusions at the oxide/ $\mathrm{SiC}$ interface during anodic oxidation would lead to a bigger surface roughness after ECMP than that after PAP is processed. The HF solution used in CARE was toxic, and Pt was particularly expensive. Ultrasonic vibration-assisted single-crystal SiC polishing and electrolyte plasma polishing (EPP) were discussed; furthermore, the research direction of further improving the surface quality and MRR of single-crystal $\mathrm{SiC}$ was prospected.

Keywords: single-crystal SiC; precision polishing; material removal rate (MRR); surface roughness

\section{Introduction}

Single-crystal $\mathrm{SiC}$ is widely considered a typical third-generation semiconductor material for the fabrication of power devices working with high voltage and high frequency and under high-temperature conditions owing to its many excellent electrical and chemical properties, such as wide energy band gap, excellent thermal conductivity, high breakdown electric field, and good chemical stability. It is an ideal substrate material for GaN-based LED, Schottky diode, MOSFET, radiation detection, and other devices [1-7]. In these power devices, the surface roughness of the $\mathrm{SiC}$ substrate seriously affects their performance; the electric breakdown field intensity and charge to breakdown have been confirmed to increase with decreasing surface roughness, which has been confirmed to increase the transconductance of a MOS transistor [8]. Therefore, to obtain an ultrasmooth surface with atomic surface roughness, which is surface damage (defects such as pits and scratches on the surface) free and subsurface damage (SSD, defects such as microcrack under the surface) free, is essential for its wide application.

Due to its particularly hard and brittle material properties and strong chemical inertness, single-crystal SiC is very difficult to process, especially in the field of precision 
polishing. After single-crystal SiC substrates undergo sawing, lapping, and mechanical polishing, there are many surface (or subsurface) damages, such as scratches and dislocations [9]. In order to reduce the surface roughness (Ra: arithmetic mean deviation; Sq: root mean square deviation) and remove surface defects, a precision polishing for single-crystal $\mathrm{SiC}$ is necessary.

Based on chemical reaction, single-crystal $\mathrm{SiC}$ precision polishing technologies have been widely investigated in recent years, such as chemical mechanical polishing (CMP) [10,11], plasma-assisted polishing (PAP) [12,13], photocatalytic chemical mechanical polishing (PCMP) [14], electrochemical mechanical polishing (ECMP) [15,16], catalyst-referred etching (CARE) [17,18], and anodic etching [19]. These studies mainly focused on improving the material removal rate (MRR) and surface quality of single-crystal SiC. One common characteristic of them, except CARE, was that the surface of single-crystal SiC was modified into a hardness oxide layer lower than that of the SiC substrate, which was then mechanically removed by a softer abrasive to achieve a smooth $\mathrm{SiC}$ surface. Although the damage-free flattening surface can be realized by these techniques, the MRR was too low or the surface roughness was not satisfactory. Therefore, the recent research focus is to develop single-crystal $\mathrm{SiC}$ precision polishing technology to achieve ultralow surface roughness more efficiently.

In this paper, precision polishing technologies for $4 \mathrm{H}-\mathrm{SiC}$ and $6 \mathrm{H}-\mathrm{SiC}$, such as $\mathrm{CMP}$, PCMP, PAP, ECMP, and CARE, were reviewed and compared with emphasis on the experimental setup, polishing mechanism, MRR, and surface roughness. Ultrasonic vibration-assisted polishing and electrolyte plasma polishing (EPP) were discussed as well, and the research direction for the surface quality and MRR's further improvement was also prospected.

\section{The Main Precision Polishing Technologies of Single-Crystal SiC}

Single-crystal $\mathrm{SiC}$ is a typical hard and brittle material, and due to its strong chemical inertness, it does not react with acid and alkali at room temperature, which makes the precise polishing of single-crystal SiC particularly difficult. The conventional mechanical polishing often introduces scratches and subsurface damage on the SiC surface, so it is generally not used as precision polishing. In the final stage of the $\mathrm{SiC}$ wafer fabrication process, a CMP process using a slurry containing chemical and silica abrasives was developed to remove subsurface damage and reduce surface roughness, and it is now industrially used. However, due to the low polishing efficiency of CMP and the difficulty of its slurry waste disposal treatment, other precision polishing technologies for single-crystal SiC were developed, such as PCMP, which introduces irradiation and $\mathrm{TiO}_{2}$ photocatalyst into CMP; PAP, which combines atmospheric-pressure plasma irradiation and soft abrasive polishing; ECMP, which combines the low-voltage electrochemical corrosion of the workpiece with soft abrasive polishing; and CARE, which uses a metal catalyst to accelerate the chemical dissolution of single-crystal $\mathrm{SiC}$ in the absence of abrasive conditions. Figure 1 presents the development of precision polishing technology of single-crystal $\mathrm{SiC}$, clearly showing its growth in popularity.

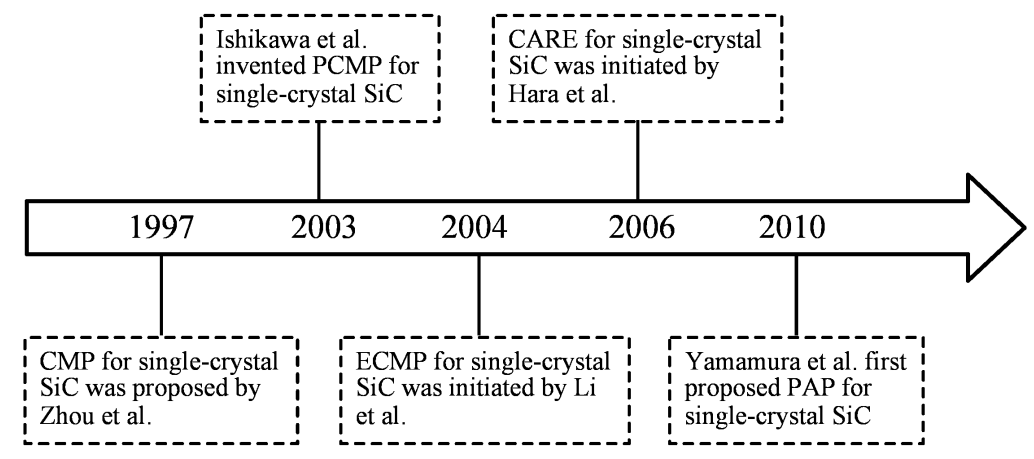

Figure 1. The development process of precision polishing technology of single-crystal SiC. 


\subsection{Chemical Mechanical Polishing (CMP)}

CMP, also known as thermal oxidation polishing, utilizes MP in conjunction with chemicals to enhance the MRR and improve surface quality [20]. Figure 2 illustrates the schematic of a typical CMP process [21]. The $\mathrm{SiC}$ wafer, which is fixed on the carrier, and the polishing pad move relative to each other under a certain pressure in the polishing slurry. Then a soft layer is formed by reactions between the oxidant of the polishing slurry and the surface of the specimen under the friction. After the soft layer is removed mechanically by the abrasive particles, a flattened $\mathrm{SiC}$ surface can be obtained. Therefore, it is a synergy result between chemical reactions and mechanical removal. The main factors affecting the MRR and surface roughness of CMP are the $\mathrm{pH}$ of slurry, abrasive, oxidant, catalyst, and so forth.

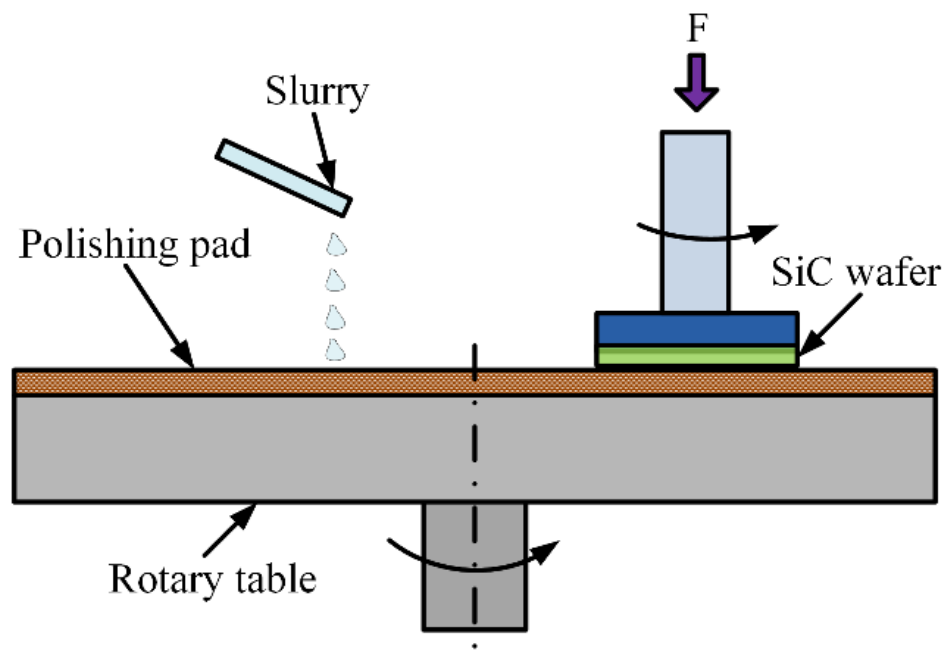

Figure 2. Schematic structure of the CMP setup [21].

CMP of single-crystal SiC was first reported by Zhou [22] in 1997. He found that chemical reactions of CMP could be improved by increasing the temperature $(\mathrm{T})$ and the $\mathrm{pH}$ of the slurry. A higher $\mathrm{pH}$ value increased the chemical reaction rate by increasing the concentration of the $\mathrm{OH}^{-}$groups, which weakened the Si-C bonds. Additionally, since chemical reactions were thermally activated processes and generally obey the Arrhenius relationship, increasing the slurry temperature and/or the temperature at the pad surface was also an effective means of enhancing the chemical etching. A smooth defect-free surface with $\mathrm{Sq}=0.5 \mathrm{~nm}$ was obtained when the $\mathrm{pH}=11$ and $\mathrm{T}=55^{\circ} \mathrm{C}$, but the MRR was very low $(<0.2 \mu \mathrm{m} / \mathrm{h})$. The results showed that the quality of CMP depended on the balance between the oxidation reaction rate and the oxide layer's removal rate. Chen [11,23] investigated the zeta potentials of $\mathrm{SiO}_{2}$ and $\mathrm{CeO}_{2}$ particles in the presence of $\mathrm{KMnO}_{4}$ in the $\mathrm{pH}$ range of 2 to 10. Both the zeta potentials of $\mathrm{SiO}_{2}$ and $\mathrm{CeO}_{2}$ particles decreased with the increase in $\mathrm{pH}$ values, as shown in Figure 3. $\mathrm{SiO}_{2}$ particles were negatively charged in the entire $\mathrm{pH}$ range, while $\mathrm{CeO}_{2}$ particles were positively charged over the $\mathrm{pH}$ range of 2-8 and negatively charged above $\mathrm{pH} 8$. The isoelectric point of $\mathrm{SiC}$ in $\mathrm{DI}$ water is about 5 . Therefore, when the $\mathrm{pH}$ value was $2 \sim 5$, the positively charged $\mathrm{SiC}$ surface was repelled by $\mathrm{CeO}_{2}$ particles. On the contrary, when the $\mathrm{pH}$ value was less than 5 , the mutual attraction between negatively charged $\mathrm{SiO}_{2}$ particles and a positively charged $\mathrm{SiC}$ surface led to the reduction of the surface oxidation area of $\mathrm{SiC}$, which would significantly reduce the friction coefficient and MRR during 6H-SiC's CMP process. Neslen [24] studied the effects of temperature, slurry $\mathrm{pH}$, applied pressure, and polishing rotation rate on the MRR of $4 \mathrm{H}-\mathrm{SiC}$ during $\mathrm{CMP}$ using a colloidal silica slurry and polyurethane/polyester fiber polishing pads. It was found that the MRR under different parameters ranged from $0.01 \mu \mathrm{m} / \mathrm{h}$ to $0.25 \mu \mathrm{m} / \mathrm{h}$. As shown in Figure 4, the change of temperature and slurry $\mathrm{pH}$ had little influence on the MRR, while the increase in pressure and polishing rotation speed would improve the MRR, and 
the polishing speed had the greatest influence. However, excessive pressure could cause damage to the polishing pad and increase the cost of wafer fabrication.

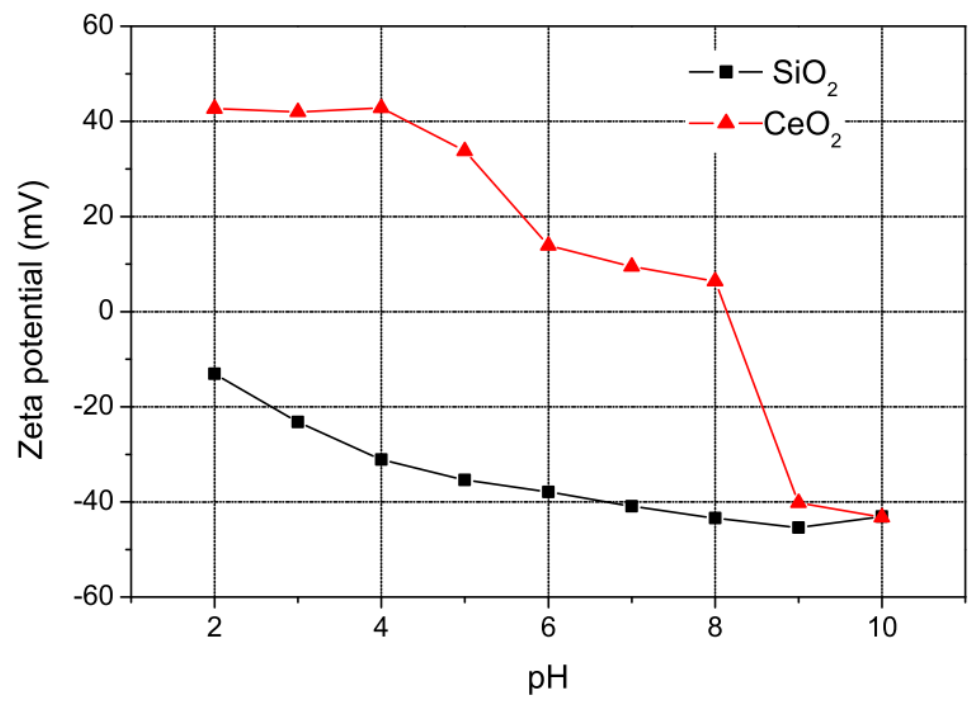

Figure 3. The zeta potentials of $\mathrm{CeO}_{2}$ and $\mathrm{SiO}_{2}$ particles in the presence of $\mathrm{KMnO}_{4}$ [23].

(a)
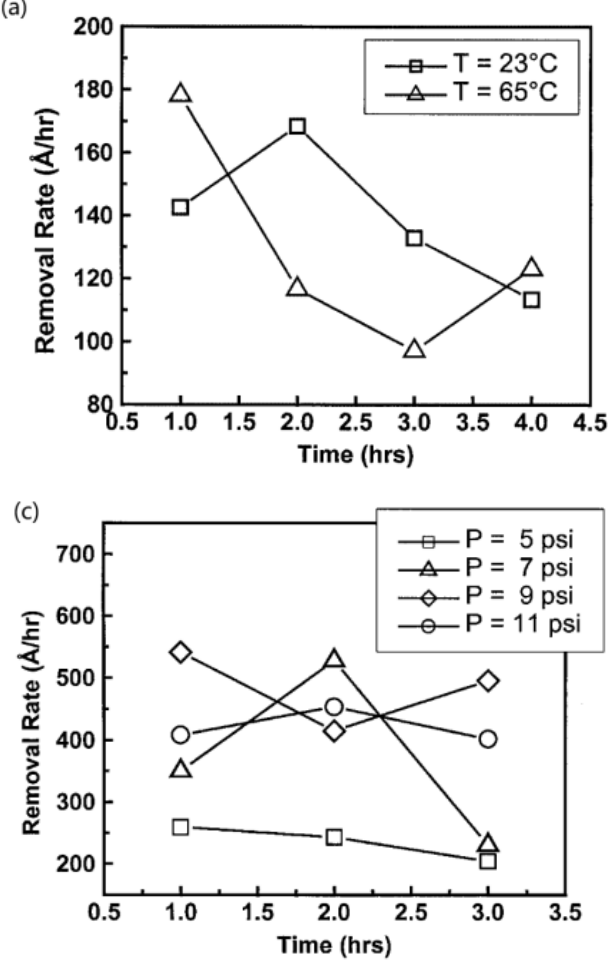

(b)

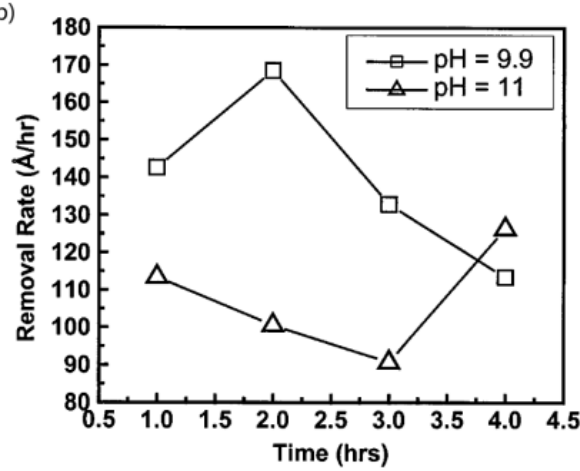

(d)

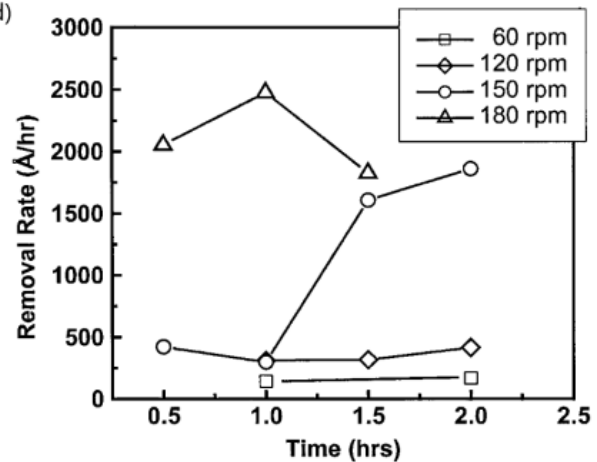

Figure 4. The effects of (a) temperature, (b) slurry $\mathrm{pH}$, (c) applied pressure, and (d) polishing rotation rate on the MRR of $4 \mathrm{H}-\mathrm{SiC}$ [24].

The oxidizing effect plays a vital role in CMP, so investigating oxidants has been a hot topic in CMP research. After decades of research, the family of typically used oxidants expanded to include dozens of members (e.g., $\mathrm{NaClO}, \mathrm{H}_{2} \mathrm{O}_{2}, \mathrm{KOH}$, and $\mathrm{KMnO}_{4}$ ). In practice, the oxidants and polishing powder are usually mixed in the slurry to obtain a high removal rate [20]. The commonly used polishing powders include colloidal silica, $\mathrm{CeO}_{2}$, nanodiamond, and $\mathrm{Al}_{2} \mathrm{O}_{3}$. 
Lee [25] used a mixed abrasive slurry (MAS) with a conventional colloidal silica slurry and nanodiamond to polish $6 \mathrm{H}-\mathrm{SiC}$. Figure 5 shows that a higher MRR was $0.32 \mu \mathrm{m} / \mathrm{h}$, and a smooth surface with lower $\mathrm{Ra}=0.27 \mathrm{~nm}$ was obtained when the concentration of the diamond abrasive was $25 \mathrm{~g} / \mathrm{L}$. Subsequently, Lee [26] focused on the mechanism of CMP SiC by alkaline MAS. CMP results showed that a higher MRR and lower surface roughness could be obtained better by MAS than by the colloidal silica slurry. As the concentration of the diamond abrasive increased, the MRR also increased. However, when the concentration was too high, it led to poor surface roughness. Figures 6 and 7 show the probable scratch removal mechanism of the colloidal silica slurry and MAS, respectively. First, the mechanically stressed areas by mechanical polishing reacted with the CMP slurry as shown in Figure 6a. Then, the colloidal silica abrasives removed the chemically reacted surface of $\mathrm{SiC}$. However, it was likely that higher MRR in the stress concentrated in areas around scratches and the lower MRR in relatively low stressed areas make the scratches on $\mathrm{SiC}$ widened from Figure $6 \mathrm{~b}$. As shown in Figure 7a,b, the diamond abrasives mechanically removed $\mathrm{SiC}$ and induced stress on the relatively low stressed surface of $\mathrm{SiC}$. The stressed areas reacted more readily with slurry chemicals and were easily smoothed with colloidal silica abrasives in Figure 7c,d. Therefore, the MAS can remove the relatively low stress area faster than the colloidal silica slurry. The high MRR of SiC in the low stressed areas effectively reduced the depth of scratches.
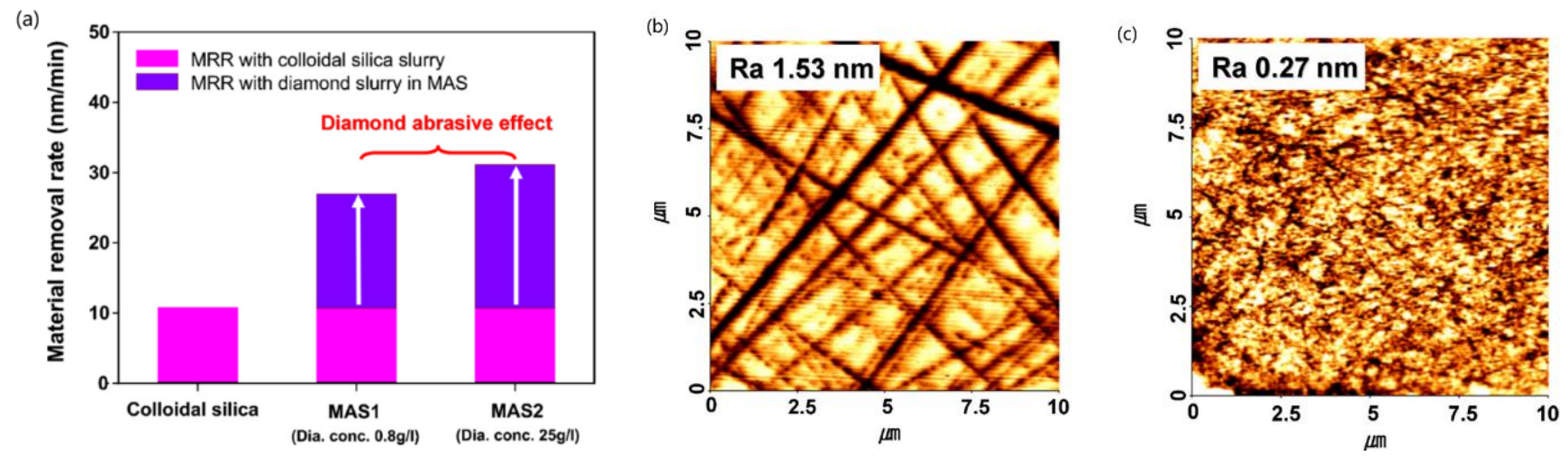

Figure 5. (a) The MRR of a 6H-SiC surface polished with a colloidal silica slurry and MAS; the AFM images and roughness values of a $6 \mathrm{H}-\mathrm{SiC}$ surface polished with (b) a colloidal silica slurry and (c) MAS (diamond concentration: $25 \mathrm{~g} / \mathrm{L}$ ) [25].
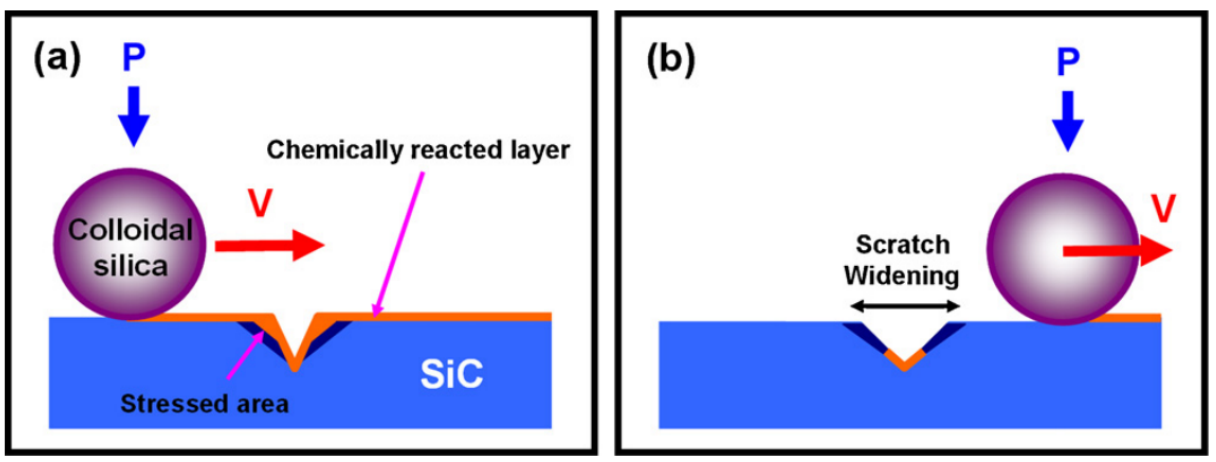

Figure 6. Probable mechanism of scratch removal in colloidal silica slurry CMP: (a) chemically reacted surface of $\mathrm{SiC}$; (b) the $\mathrm{SiC}$ surface after chemically reacted layer removed by colloidal silica [26]. 

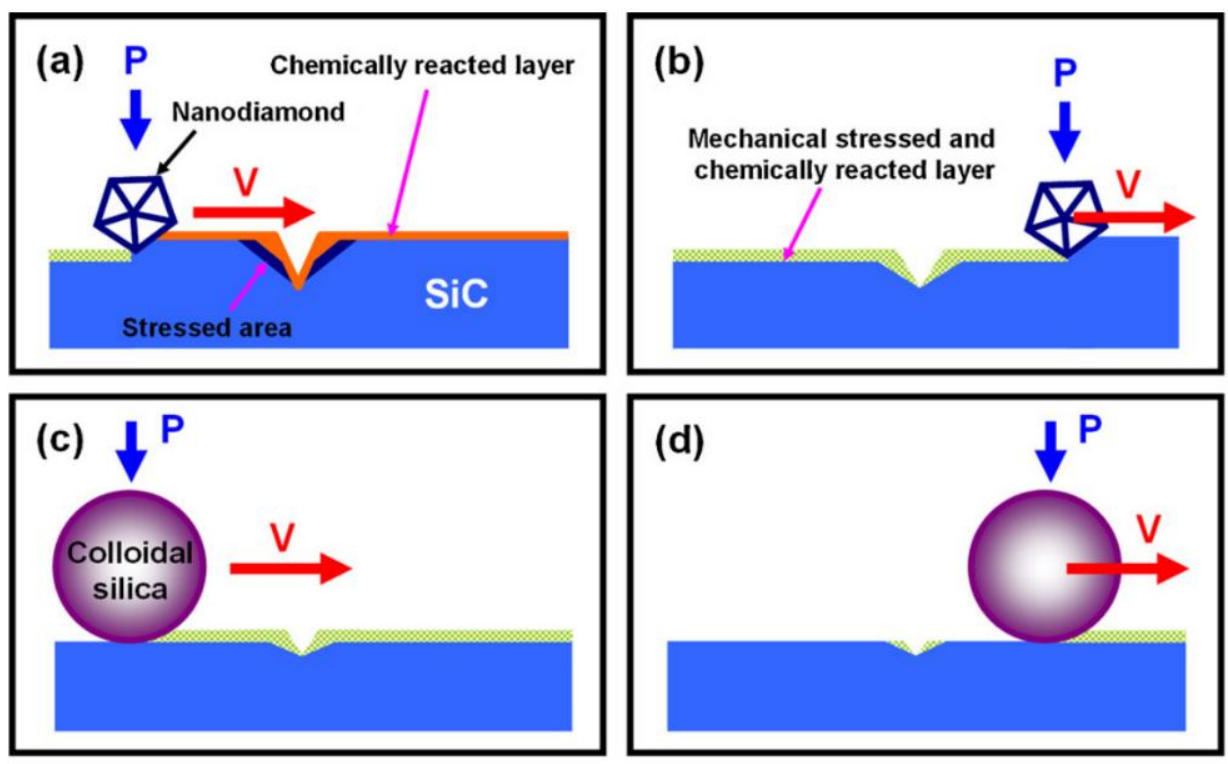

Figure 7. Probable mechanism of scratch removal in MAS CMP: (a) chemically reacted surface of $\mathrm{SiC}$; (b) the SiC surface after chemically reacted layer removed by nanodiamonds; (c) the mechanical stressed and chemically reacted layer before removed by colloidal silica; (d) the SiC surface after chemically reacted layer removed by colloidal silica [26].

Heydemann [27] found that MRR can be improved to $0.60 \mu \mathrm{m} / \mathrm{h}$ by adding nanodiamond with a diameter of $0.1 \mathrm{~nm}$ into the conventional colloidal silica slurry during $6 \mathrm{H}-\mathrm{SiC}$ 's CMP, which was 10 times higher than that of conventional colloidal silica slurry $\mathrm{CMP}$, and the surface roughness ( $\mathrm{Ra})$ was $0.55 \mathrm{~nm}$. A sodium hypochlorite $(\mathrm{NaClO})$ oxidant was added to the aforementioned mixed abrasive slurry, and then the polishing effect was further improved so that the MRR increased to $0.92 \mu \mathrm{m} / \mathrm{h}$, and the surface roughness Ra decreased to $0.52 \mathrm{~nm}$. A research by An [28] also proved that the CMP performance of SiC wafers could be improved by the oxidant $(\mathrm{NaClO})$. $6 \mathrm{H}-\mathrm{SiC}^{\prime} \mathrm{s} \mathrm{CMP}$ was conducted in the slurry, which contained nanodiamond, potassium hydroxide $(\mathrm{KOH})$, colloidal silica slurry, and $\mathrm{NaClO}$, and then a significant MRR value of $0.937 \mu \mathrm{m} / \mathrm{h}$ and a favorable surface $(\mathrm{Ra}=$ $0.108 \mathrm{~nm}$ ) without defects were obtained. This was due to the chemical reaction enhanced by $\mathrm{NaClO}$, which caused a thicker $\mathrm{SiO}_{2}$ layer to form.

Pan and Zhou $[10,29]$ applied a slurry containing $\mathrm{H}_{2} \mathrm{O}_{2}, \mathrm{KOH}$, and colloidal silica abrasives to the chemical mechanical polishing of $6 \mathrm{H}-\mathrm{SiC}$. The relationships between the MRR of the $\mathrm{SiC}$ wafer and three components are shown in Figure 8. It was found that the MRR of the $\mathrm{SiC}$ wafer increased as the content of $\mathrm{H}_{2} \mathrm{O}_{2}$ increased when it was below $6 \mathrm{wt} \%$. The MRR increased with the increment of $\mathrm{KOH}$ content until $0.6 \mathrm{wt} \%$. The MRR presents a decline trend when the $\mathrm{KOH}$ content is above $0.6 \mathrm{wt} \%$. As shown in Figure $8 \mathrm{c}$, the MRR demonstrated a climbing variation with the increment of the abrasive silica colloidal content below $30 \mathrm{wt} \%$. The MRR was in proportion to silica particles' content basically. The CMP mechanism of the $6 \mathrm{H}-\mathrm{SiC}$ wafer is illustrated in Figure 9. During the CMP process, the transient heat generated by friction between the wafer and the polishing pad promoted the decomposition of $\mathrm{H}_{2} \mathrm{O}_{2}$ and the release of enough hydroxyl radicals. Through the hydroxyl radical and oxygen, $\mathrm{SiC}$ could be oxidized to a softer and more chemically reactive $\mathrm{SiO}_{2}$ layer. $\mathrm{SiO}_{2}$ reacted with $\mathrm{OH}^{-}$to form a soluble $\mathrm{SiO}_{3}{ }^{2-}$; meanwhile, $\mathrm{SiO}_{3}{ }^{2-}$ was removed by the colloidal silica abrasive, thereby polishing the $\mathrm{SiC}$ wafer effectively. Controlling the balance between mechanical wear and chemical reactions in CMP by adjusting the content of different components played a key role in obtaining a high MRR and atomically flatting defect-free surface with a step/terrace structure. The optimum polishing slurry composition was obtained by the experiment: $\mathrm{H}_{2} \mathrm{O}_{2} 6 \mathrm{wt} \%, \mathrm{KOH} 0.6 \mathrm{wt} \%$, and colloidal silica $30 \mathrm{wt} \%$. A maximum MRR of $0.105 \mu \mathrm{m} / \mathrm{h}$ could be obtained by CMP with this slurry. 
At the same time, a smooth defect-free surface with a step/terrace structure was obtained after polishing, and Ra measured by a white light interferometer was $0.174 \mathrm{~nm}$.

(a)

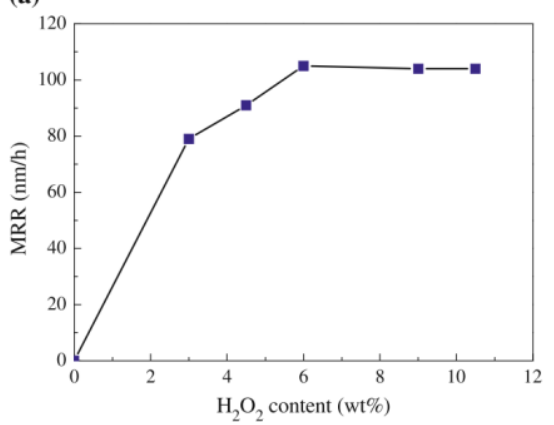

(b)

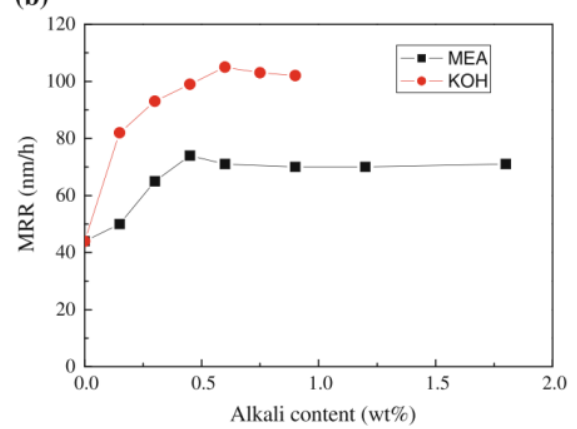

(c)

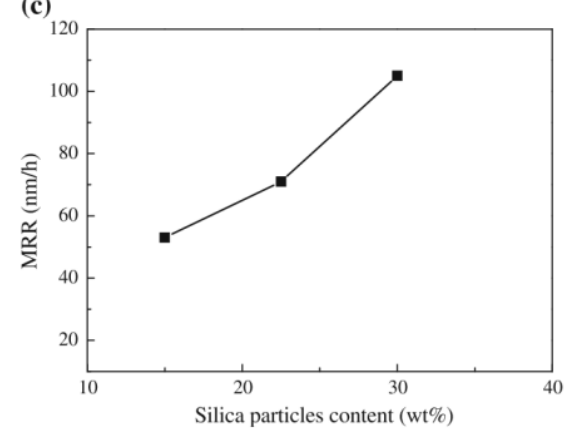

Figure 8. The relationship between the MRR of a $\mathrm{SiC}$ wafer and (a) $\mathrm{H}_{2} \mathrm{O}_{2}$ content, with $0.6 \mathrm{wt} \% \mathrm{KOH}$ and $30 \mathrm{wt} \%$ silica particles; (b) different alkali ( $\mathrm{KOH}$ or MEA) contents, with $6 \mathrm{wt} \% \mathrm{H}_{2} \mathrm{O}_{2}$ and $30 \mathrm{wt} \%$ silica particles; and (c) silica particle content, with $0.6 \mathrm{wt} \% \mathrm{KOH}$ and $6 \mathrm{wt} \% \mathrm{H}_{2} \mathrm{O}_{2}$ [10].

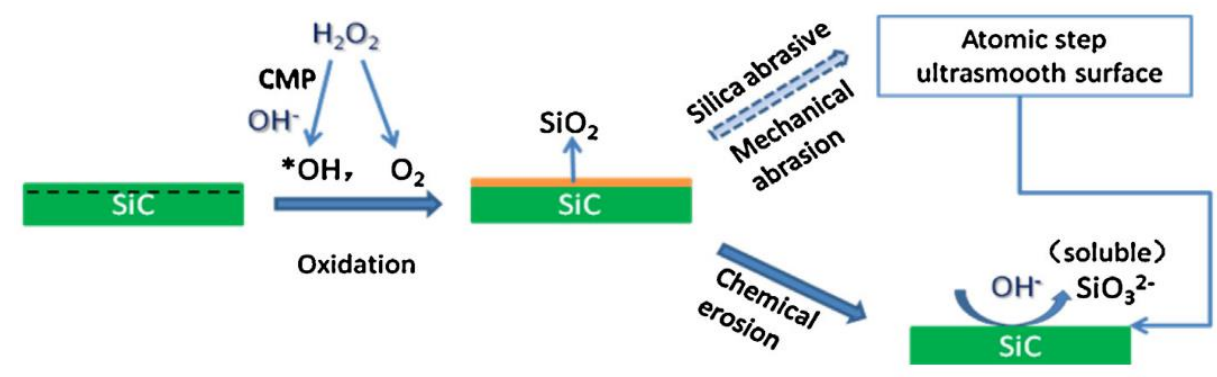

Figure 9. Probable mechanism of scratch removal in MAS CMP [29].

Chen [11,23] adopted $\mathrm{KMnO}_{4}$ as the oxidant to study the $6 \mathrm{H}-\mathrm{SiC}^{\prime} \mathrm{C}$ CMP properties with an $\mathrm{SiO}_{2}$ and $\mathrm{CeO}_{2}$ abrasive. The results showed that the maximum MRR $(1.089 \mu \mathrm{m} / \mathrm{h})$ and a smooth surface with Ra of $0.11 \mathrm{~nm}$ could be obtained by the slurry that contained $2 \mathrm{wt} \% \mathrm{CeO}_{2}$ and $0.05 \mathrm{M} \mathrm{KMnO}_{4}$ at a $\mathrm{pH}$ value of 2 . On the other hand, using a slurry containing $6 \mathrm{wt} \% \mathrm{SiO}_{2}$ and $0.05 \mathrm{M} \mathrm{KMnO}_{4}$ with a $\mathrm{pH}$ value of 6 , the surface roughness of Ra was $0.254 \mathrm{~nm}$, and the maximum MRR was only $0.185 \mu \mathrm{m} / \mathrm{h}$. In addition, during the CMP process of silicon carbide, a Si-O-Ce bond was formed between ceria particles and the oxide layer and then removed rapidly by mechanical abrasion force [30]. The physical and chemical reaction of $\mathrm{CeO}_{2}$ could lead to a higher MRR of SiC CMP, especially in the strong acid $\mathrm{KMnO}_{4}$ environment. Tsai [31] processed CMP of $4 \mathrm{H}-\mathrm{SiC}$ under a self-made polyurethane polishing pad with nanodiamond impregnated by the slurry, which contained $\mathrm{Al}_{2} \mathrm{O}_{3}$ abrasives and $\mathrm{KMnO}_{4}$. The results indicated that a defect-free smooth surface with an Ra of $0.443 \mathrm{~nm}$ could be effectively obtained in the case of the polishing pad embedded with $5 \mathrm{wt} \%$ nanodiamond abrasives, and the MRR could reach $1.3 \mu \mathrm{m} / \mathrm{h}$.

In summary, CMP combines mechanical wear and chemical oxidation reactions to realize reasonable material removal efficiency and ultrafine polishing of single-crystal $\mathrm{SiC}$. Controlling the balance between mechanical wear and chemical reactions in CMP by adjusting the parameters plays a key role in obtaining high MRR and atomically flatting a defect-free surface. However, its MRR is extremely low, about $0.5 \sim 1.3 \mu \mathrm{m} / \mathrm{h}$; furthermore, the waste treatment is difficult and expensive [32,33].

\subsection{Photocatalytic Chemical Mechanical Polishing (PCMP)}

As shown in Figure 10, a single-crystal $\mathrm{SiC}$ wafer is adhered to the bottom of the polishing head. A lot of $\mathrm{TiO}_{2}$ particles are used to prepare the slurry. Photogenerated electrons and holes are generated on the surface of $\mathrm{TiO}_{2}$ particles by $\mathrm{UV}$ light irradiation. $\mathrm{H}_{2} \mathrm{O}$ and $\mathrm{OH}^{-}$adsorbed on the surface of $\mathrm{TiO}_{2}$ particles can be oxidized into the hydroxyl 
radicals $(\bullet \mathrm{OH})$ with a strong oxidizing property by photogenerated holes. Then the surface of single-crystal $\mathrm{SiC}$ would be oxidized to $\mathrm{SiO}_{2}$, which can be easily removed under the mechanical friction of abrasive particles, and finally, the atomic flat surface of single-crystal $\mathrm{SiC}$ can be realized. We call this method PCMP.

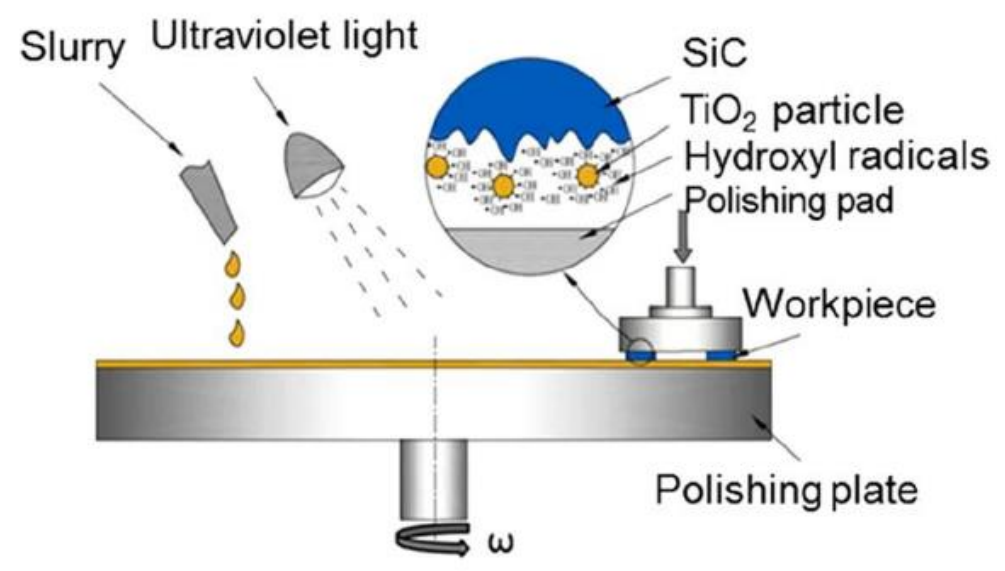

Figure 10. Schematic of the PCMP setup [14].

Ishikawa [34] used $\mathrm{TiO}_{2}$ as a photocatalyst to conduct surface modification of singlecrystal $\mathrm{SiC}$ at room temperature. It was found that with a $\mathrm{TiO}_{2}$ photocatalyst, $\bullet \mathrm{OH}$ with a strong oxidizing ability could be produced, which could promote the oxidation efficiency of $\mathrm{SiC}$ into $\mathrm{SiO}_{2}$. The reaction was as follows:

$$
\mathrm{SiC}+4 \bullet \mathrm{OH}+\mathrm{O}_{2}=\mathrm{SiO}_{2}+2 \mathrm{H}_{2} \mathrm{O}+\mathrm{CO}_{2} \uparrow
$$

Although the oxidation rate was very low, a nanometer surface without subsurface damage could be obtained after photocatalytic treatment of single-crystal silicon carbide by $\mathrm{TiO}_{2}$.

Ohnishi [35] added $0.3 \mathrm{wt} \% \mathrm{TiO}_{2}$ to the alkaline slurry with $\mathrm{SiO}_{2}$ and found that the polishing efficiency of $4 \mathrm{H}-\mathrm{SiC}$ could be improved significantly by UV irradiation, which was caused by some chemical substances with strong oxidation produced by the photocatalytic reaction of $\mathrm{TiO}_{2}$ particles under UV irradiation, promoting the oxidation of the SiC surface.

$\mathrm{A} \mathrm{TiO}_{2}$ thin layer was deposited on the nanodiamond (ND) abrasive to polish a $6 \mathrm{H}-\mathrm{SiC}$ wafer under UV irradiation in Lu's report [36]. Through comparative experiments, it was indicated that the MRR was about $0.115 \mu \mathrm{m} / \mathrm{h}$ using the $\mathrm{ND} / \mathrm{TiO}_{2}$ composite abrasive polishing pad under UV irradiation, which was almost twice the pristine diamond abrasive, and a smooth surface of the $\mathrm{SiC}$ with an $\mathrm{Ra}$ of $0.915 \mathrm{~nm}$ was obtained. This was due to the $\mathrm{SiC}$ being oxidized by $\bullet \mathrm{OH}$, which increased upon exposure to UV irradiation when applying the $\mathrm{ND} / \mathrm{TiO}_{2}$ composite abrasive pad and forming a soft $\mathrm{SiO}_{2}$ layer.

Yuan [14] confirmed that the PCMP of $4 \mathrm{H}-\mathrm{SiC}$ required a photocatalyst, UV light, electron capturer, and acid environment, according to the results of the oxidation reduction potential experiment and the static oxidation experiment. As seen from Figure 11, among the prepared five PCMP slurries as shown in Table 1, the highest MRR of $0.95 \mu \mathrm{m} / \mathrm{h}$ and the best surface finish ( $\mathrm{Ra}=0.35 \mathrm{~nm}$ ) could be provided by slurry $1 \#$. The schematic diagram of the polishing mechanism of SiC PCMP is shown in Figure 12, and hydroxyl radicals could be generated on the surface of the nano- $\mathrm{TiO}_{2}$ particles in the slurry under UV irradiation. $\mathrm{H}_{2} \mathrm{O}_{2}$ captured electrons to prevent the recombination of an electron and hole and the produced hydroxyl radicals. These strong oxidants flowed to the surface of the $\mathrm{SiC}$ wafer with the rotation of the polishing pad. Additionally, SiC on the wafer surface was oxidized into a soft $\mathrm{SiO}_{2}$ layer, which was easily removed by abrasives. The oxidization was a progressive process that occurred in various forms of functional groups with $\mathrm{Si}-\mathrm{C}-\mathrm{O}$, $\mathrm{Si}-\mathrm{O}, \mathrm{C}-\mathrm{O}$, and $\mathrm{C}=\mathrm{O}$ included. Owing to the mechanical removal of the soft layer at the nanolevel, an atomic ultrasmooth $4 \mathrm{H}-\mathrm{SiC}$ surface could be obtained by PCMP. 


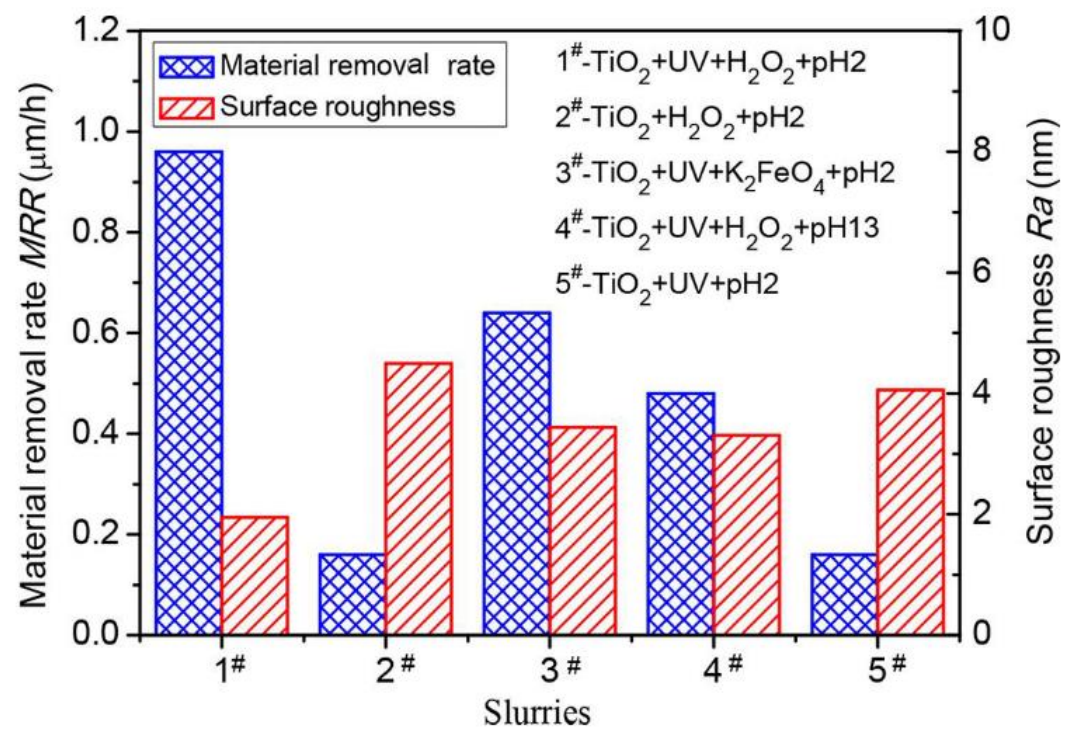

Figure 11. Surface roughness and material removal rate of $\mathrm{SiC}$ polished by different slurries [14].

Table 1. Different slurries for PCMP of $4 \mathrm{H}-\mathrm{SiC}[14]$.

\begin{tabular}{ccccccc}
\hline No. & Photocatalysis & UV & Electron Capturer & $\mathbf{p H}$ & Abrasive & Dispersant \\
\hline $1 \#$ & $\mathrm{TiO}_{2}$ & $\mathrm{UV}$ & $\mathrm{H}_{2} \mathrm{O}_{2}$ & 2 & $\mathrm{SiO}_{2}$ & $\left(\mathrm{NaPO}_{3}\right)_{6}$ \\
$2 \#$ & $\mathrm{TiO}_{2}$ & - & $\mathrm{H}_{2} \mathrm{O}_{2}$ & 2 & $\mathrm{SiO}_{2}$ & $\left(\mathrm{NaPO}_{3}\right)_{6}$ \\
$3 \#$ & $\mathrm{TiO}_{2}$ & $\mathrm{UV}$ & $\mathrm{K}_{2} \mathrm{FeO}$ & 2 & $\mathrm{SiO}_{2}$ & $\left(\mathrm{NaPO}_{3}\right)_{6}$ \\
$4 \#$ & $\mathrm{TiO}_{2}$ & $\mathrm{UV}$ & $\mathrm{H}_{2} \mathrm{O}_{2}$ & 13 & $\mathrm{SiO}_{2}$ & $\left(\mathrm{NaPO}_{3}\right)_{6}$ \\
$5 \#$ & $\mathrm{TiO}_{2}$ & $\mathrm{UV}$ & - & 2 & $\mathrm{SiO}_{2}$ & $\left(\mathrm{NaPO}_{3}\right)_{6}$ \\
\hline
\end{tabular}

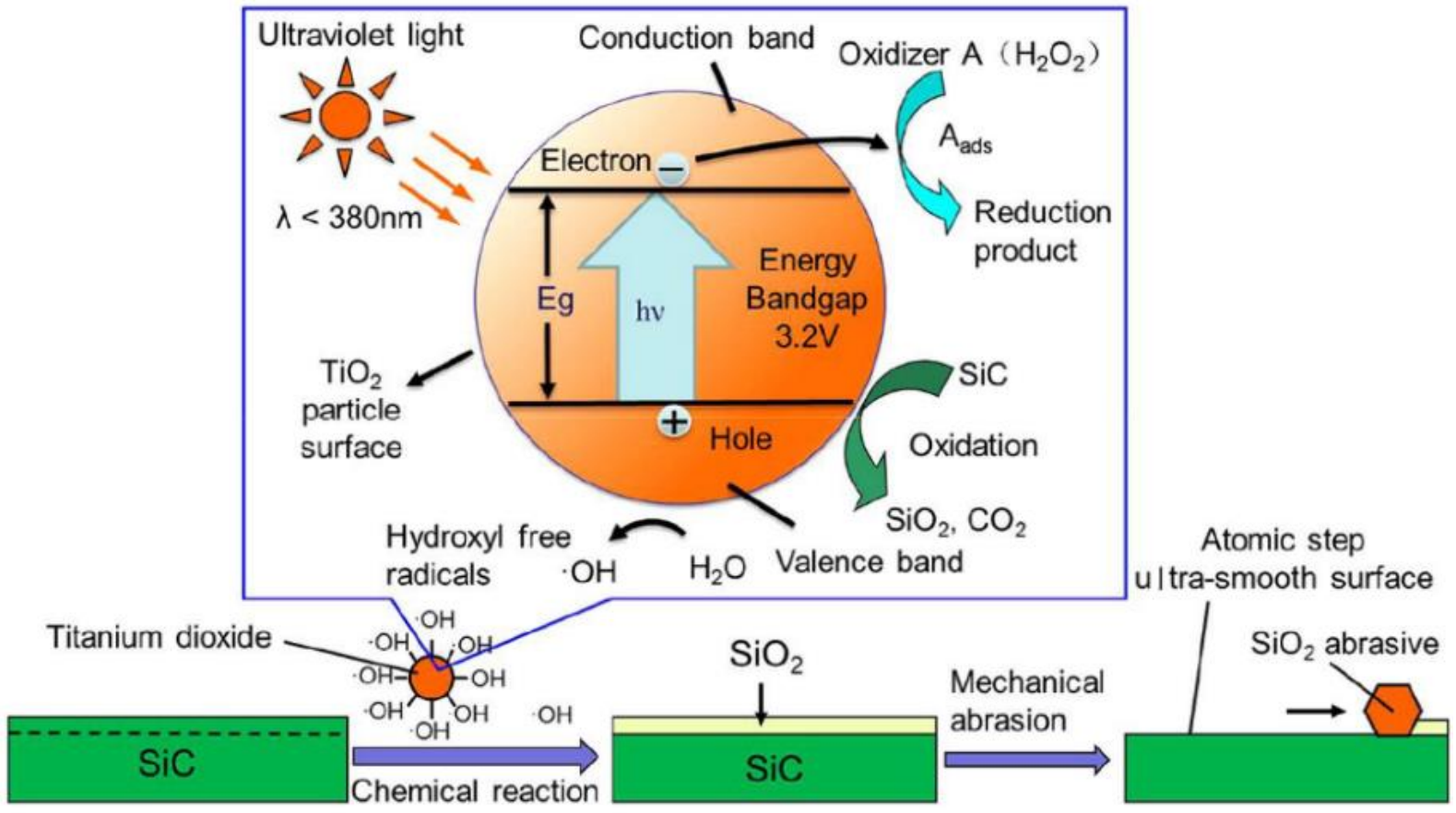

Figure 12. Schematic diagram of the mechanism of SiC PCMP [14].

Due to the nontoxicity of the photocatalyst $\mathrm{TiO}_{2}, \mathrm{PCMP}$ is environmentally friendly. Although PCMP is effective for single-crystal SiC flatting, the MRR is relatively low (the highest is about $1 \mu \mathrm{m} / \mathrm{h}$ ). 


\subsection{Plasma-Assisted Polishing (PAP)}

$\mathrm{PAP}$ is a precise polishing technology combining atmospheric plasma irradiation with soft abrasive polishing. Figure 13 shows a schematic of the PAP setup. This setup consists of separately installed plasma generation and mechanical removal parts. The oxide layer can be formed on the single-crystal $\mathrm{SiC}$ surface by the atmospheric plasma irradiation. An atomic smooth single-crystal $\mathrm{SiC}$ surface without internal stress and SSD can be obtained after the oxide layer is removed by the mechanical removal parts.

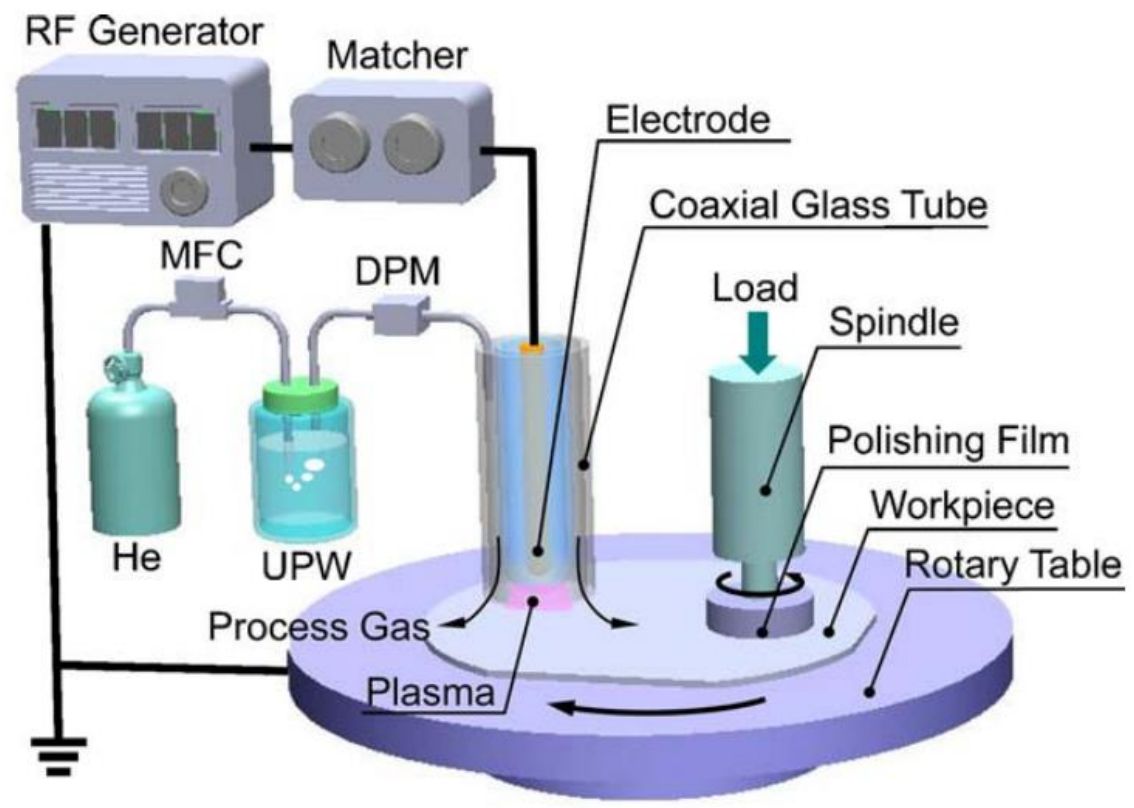

Figure 13. Schematic of PAP setup [37].

Yamamura [12] proposed a novel precise polishing technology of 4H-SiC, which was assisted by atmospheric plasma in 2010. The results of EDX and nanoindentation showed that a soft oxide film was formed on the $\mathrm{SiC}$ surface by water vapor or oxygen plasma irradiation, and the surface hardness decreased from 37.38 GPa to $4.53 \mathrm{GPa}$. The spectroscopic results, as shown in Figure 14a,b, revealed that the main surface modification active substances in water vapor plasma and oxygen plasma were $\bullet \mathrm{OH}$ and $\bullet \mathrm{O}$, respectively. Owing to the greater oxidation potential of $\bullet \mathrm{OH}(2.80 \mathrm{~V})$, compared with that of $\bullet \mathrm{O}(2.42 \mathrm{~V})$, the oxidation capacity of $\bullet \mathrm{OH}$ was higher than that of $\bullet \mathrm{O}$, so the MRR of $\mathrm{SiC}$ by the radiation of water vapor plasma was superior to that of oxygen plasma. A smooth surface without scratches and subsurface damage was obtained by water vapor plasma-assisted polishing using the polishing film with $\mathrm{CeO}_{2}$ abrasive particles, and AFM results, as shown in Figure 14c,d, revealed that the surface roughness Sq decreased from $0.495 \mathrm{~nm}$ to $0.06 \mathrm{~nm}$. Deng [38] also obtained the same results of surface roughness variation. Many swell-like structures along the deep scratches on the surface were observed after the irradiation of water vapor plasma rather than along the shallow scratches in Figure 15a,b. It was assumed that the lattice strain remaining in the vicinity of the deep scratches, which was larger than that of shallow scratches, enhanced the local oxidation. This caused the damaged area to be preferentially removed by subsequent abrasive polishing. XPS results in Figure 15c showed that the $4 \mathrm{H}-\mathrm{SiC}$ surface after plasma oxidation contained not only $\mathrm{SiO}_{2}$ but also the interface oxidation product $\mathrm{Si}_{4} \mathrm{C}_{4-\mathrm{x}} \mathrm{O}_{2}$. The same interface oxidation product, $\mathrm{Si}_{4} \mathrm{C}_{4-\mathrm{x}} \mathrm{O}_{2}$, was also verified in Yamamura's study [37]. In his study, it was also found that the surface of $4 \mathrm{H}-\mathrm{SiC}$ after plasma polishing exhibited a step/terrace structure corresponding to the inclination of the crystal plane, and the surface roughness Sq decreased from $0.42 \mathrm{~nm}$ to $0.14 \mathrm{~nm}$. 

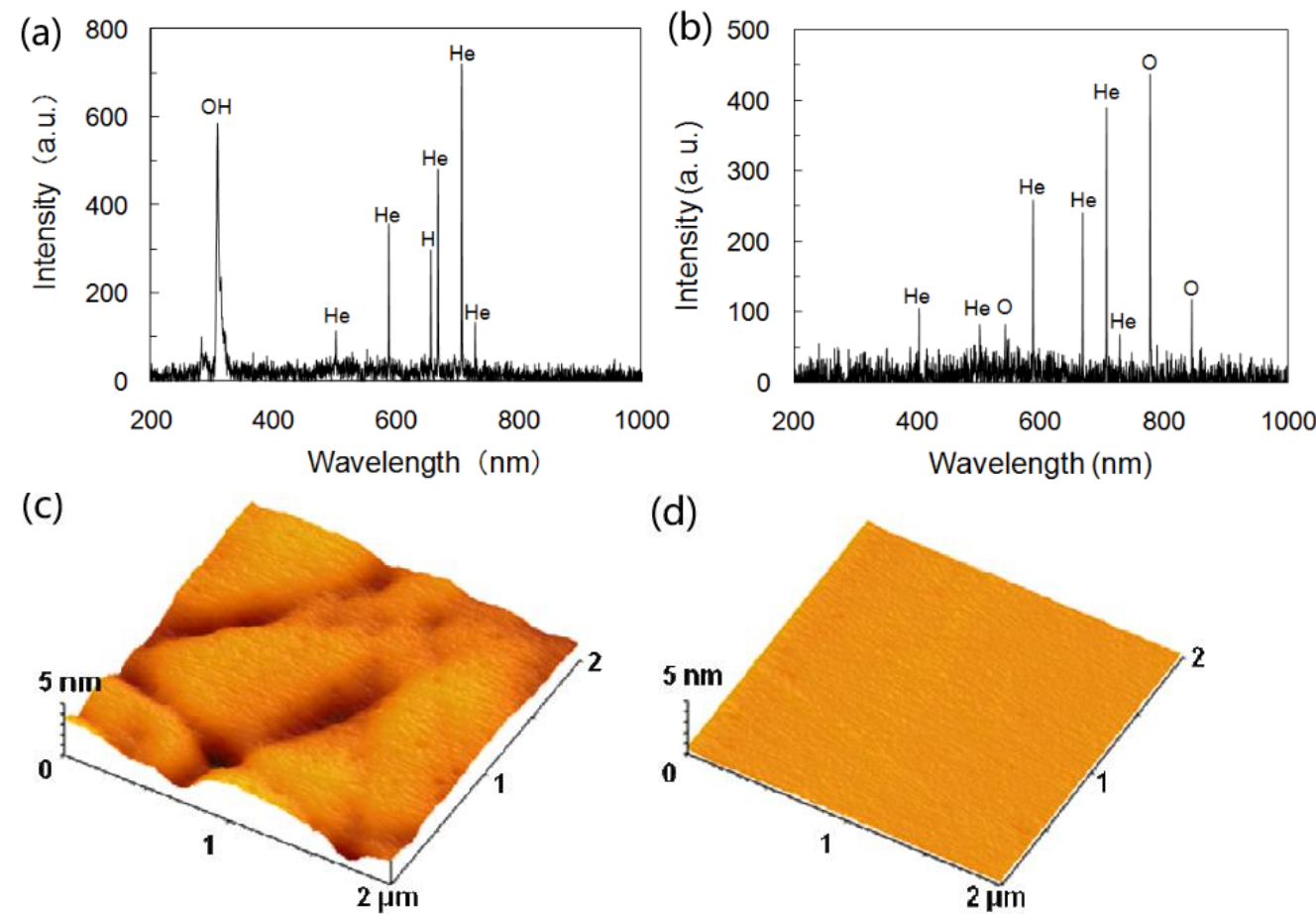

Figure 14. Emission spectra of the plasma: (a) water vapor plasma, (b) oxygen plasma; AFM images of $4 \mathrm{H}-\mathrm{SiC}$ : (c) unprocessed surface at $0.495 \mathrm{~nm} \mathrm{rms}$, (d) surface after PAP at $0.060 \mathrm{~nm} \mathrm{rms}$ [12].
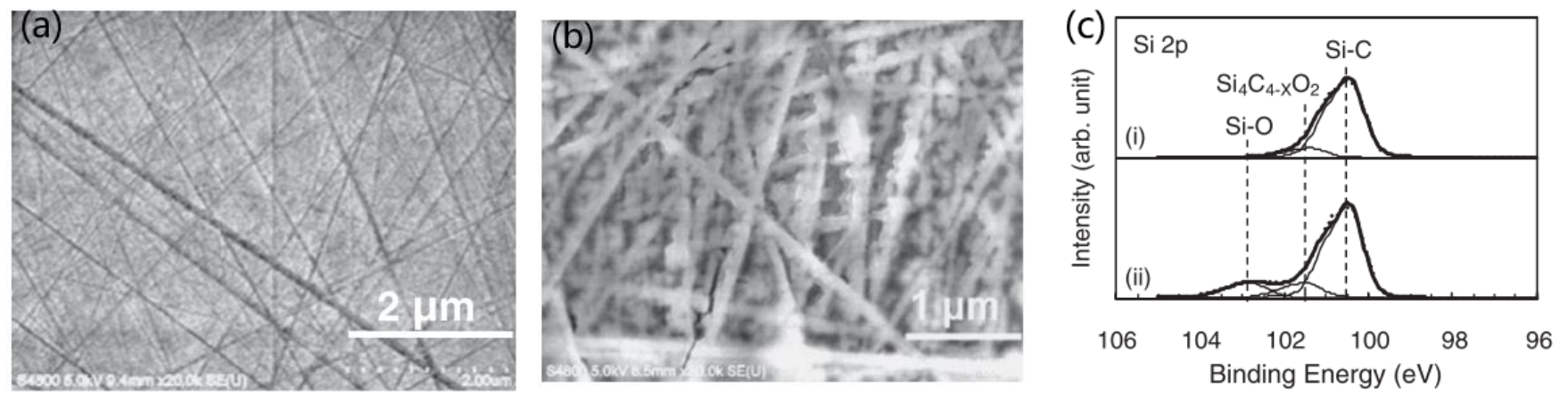

Figure 15. SEM images of SiC surface: (a) unprocessed surface and (b) processed surface irradiated by water vapor plasma; (c) XPS spectra of $4 \mathrm{H}-\mathrm{SiC}$ Si2p [38].

The selection of abrasive material also greatly affected the morphology of PAPprocessed surfaces. Deng [39] studied the surface characteristics of $4 \mathrm{H}-\mathrm{SiC}(0001)$ after PAP by different abrasives. Effective oxidation was obtained on the surface after plasma irradiation; besides $\mathrm{SiO}_{2}$ as the main product, there was an interface product with insufficient oxidation named $\mathrm{Si}_{4} \mathrm{C}_{4-x} \mathrm{O}_{2}$ whose hardness was between $\mathrm{SiC}$ and $\mathrm{SiO}_{2}$. As shown in Figure 16a,b, the irregular step/terrace structure and some short and shallow scratches on the surface were generated after PAP using $\mathrm{Al}_{2} \mathrm{O}_{3}$ abrasives, while a regular step/terrace structure surface without any scratches and subsurface damage was generated after PAP using $\mathrm{CeO}_{2}$ abrasives. After the oxide layer was removed, $\mathrm{Al}_{2} \mathrm{O}_{3}$ would polish the $\mathrm{SiC}$ substrate, resulting in surface scratches because the hardness of $\mathrm{Al}_{2} \mathrm{O}_{3}$ was similar to that of $\mathrm{SiC}$. However, the hardness of $\mathrm{CeO}_{2}$ was close to that of the oxidized layer, leading to only the oxide layer being removed and no further damage being introduced. Scanning white light interferometer images of the $\mathrm{SiC}$ surface processed by PAP with $\mathrm{CeO}_{2}$ abrasives showed that there were no scratches on the surface and the surface roughness Sq decreased to $0.20 \mathrm{~nm}$. 

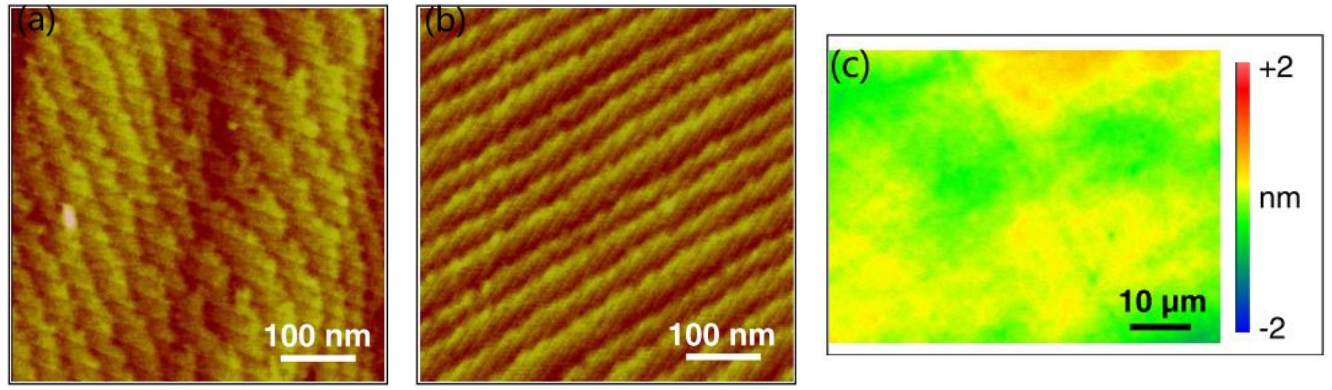

Figure 16. AFM images of the surface processed by PAP using (a) $\mathrm{Al}_{2} \mathrm{O}_{3}$ abrasives, (b) $\mathrm{CeO}_{2}$ abrasives; (c) SWLI image of the surface processed by PAP using $\mathrm{CeO}_{2}$ abrasives [39].

Deng [40] found that the oxidation products of $4 \mathrm{H}-\mathrm{SiC}$ processed by $\mathrm{PAP}$ were $\mathrm{SiO}_{2}$, which was the uppermost layer, and silicon oxycarbide, which was an intermediate layer with a very thin thickness. With the increase in plasma oxidation time, not only the thickness of $\mathrm{SiO}_{2}$ but also the thickness of the silicon oxycarbide layer increased. It was also pointed out that in the PAP process, the optimization of the ratio of the oxide layer removal rate and plasma oxidation rate was crucial to obtain the atomic smooth $\mathrm{SiC}$ surface without a residual oxide layer.

Deng [41] used an XTEM image, as shown in Figure 17c, to prove that the interface between the oxide layer and $\mathrm{SiC}$ was very flat, which was the main reason for the smooth surface after polishing. In addition, by comparing the XPS spectra (Si2p) of the $4 \mathrm{H}-\mathrm{SiC}$ surface in Figure 17a,b, the silicon oxycarbide layer cannot be removed by HF corrosion, but can be mechanically removed by a $\mathrm{CeO}_{2}$ abrasive. The probable mechanism of scratch removal can be seen in Figure 17d,e. After PAP of $4 \mathrm{H}-\mathrm{SiC}$ with $\mathrm{CeO}_{2}$ abrasives for $1 \mathrm{~h}$, the atomic surface $(\mathrm{Sq}=0.17 \mathrm{~nm})$ with a step/terrace structure was obtained, and the MRR was $0.080 \mu \mathrm{m} / \mathrm{h}$.
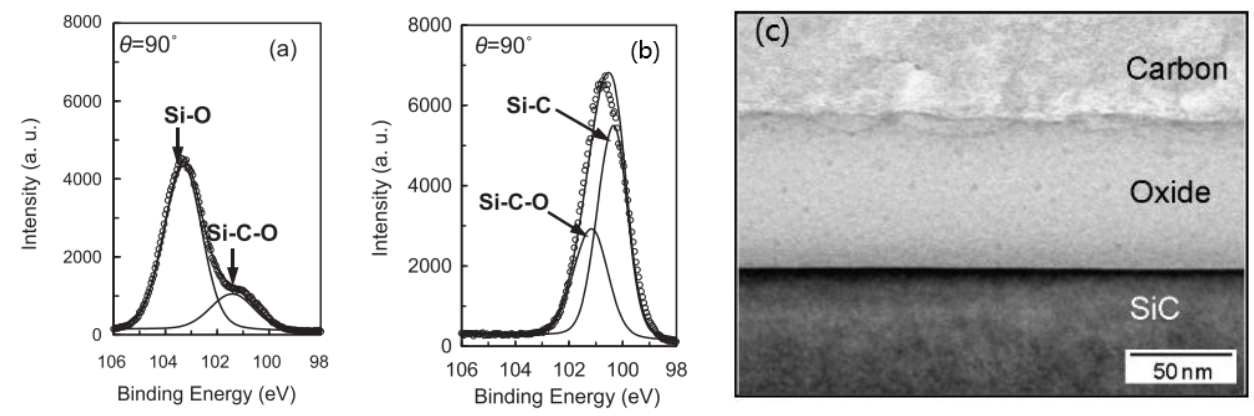

(d)

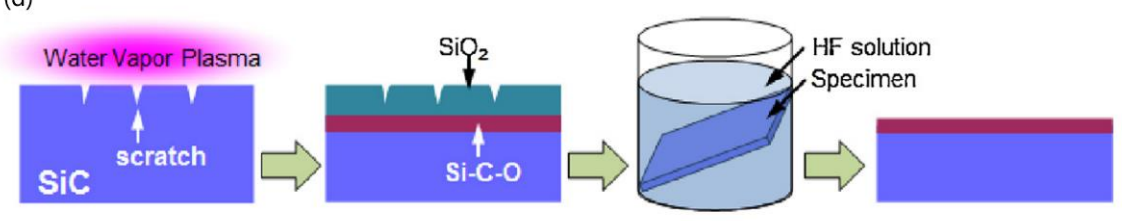

(e)

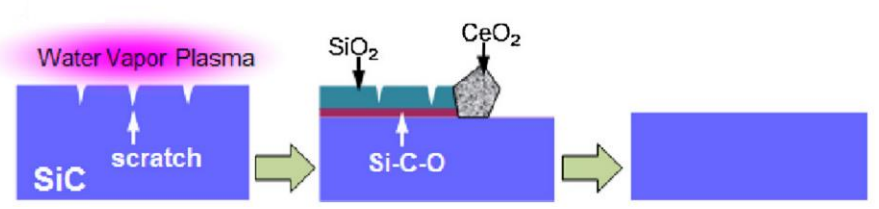

Figure 17. ARXPS spectra (Si2p) of $4 \mathrm{H}-\mathrm{SiC}$ surface (a) by water vapor plasma irradiated, (b) the surface in (a) after HF dipping, (c) XTEM image of a surface irradiated by water vapor plasma for 1 $\mathrm{h}$, probable mechanism of scratch removal (d) by plasma oxidation and HF dipping and (e) by PAP using ceria abrasives [41]. 
Deng [42] carried out an experimental study on the steam plasma oxidation (PO) and thermal oxidation (TO) of $4 \mathrm{H}-\mathrm{SiC}$, and it indicated that the initial oxidation rate of water vapor plasma oxidation $(0.185 \mu \mathrm{m} / \mathrm{h})$ was much higher than that of thermal oxidation $(0.029 \mu \mathrm{m} / \mathrm{h})$. In the case of water vapor plasma oxidation, the oxide/SiC interface was rough when the oxide layer was thin. As the oxide layer thickness increased, the oxide/SiC interface became flat. In contrast, the oxide/ $\mathrm{SiC}$ interface was flat regardless of the oxide layer thickness for thermal oxidation. The following study by Deng [43] found that there were two main reasons why the initial oxidation rate of PO was higher than that of TO: first, the oxidation potential of $\bullet \mathrm{OH}$ was much higher than that of $\bullet \mathrm{O}$. Second, $\bullet \mathrm{OH}$ was much smaller than that of an oxygen molecule. Therefore, it was easier for it to pass through the oxide layer and react with $\mathrm{SiC}$ at the interface of the oxide and $\mathrm{SiC}$ at a higher speed, and then a higher oxidation rate was obtained, especially at the initial oxidation stage. Thus, when the oxide layer was relatively thin, it was difficult to achieve the uniform diffusion of $\bullet \mathrm{OH}$ across the entire surface. This was the reason why the interface was rough at the initial stage of oxidation. For the thicker oxide layer, it was more difficult for $\bullet \mathrm{OH}$ to diffuse through the oxide layer. In this case, the diffusion of $\bullet \mathrm{OH}$ was more uniform in the transverse direction. Therefore, as the oxide layer thickness increased in PO, the interface would become flat. The $\mathrm{SiC}$ surface treated with $\mathrm{TO}$ produced many pits, but no pits appeared for the $\mathrm{SiC}$ surface treated with $\mathrm{PO}$. These pits were caused by preferential oxidation of defects in $\mathrm{SiC}$, which is thought to be most affected by the high oxidation temperature in TO [44].

During the oxidation of $4 \mathrm{H}-\mathrm{SiC}$ by plasma, Deng [45] found that the content of water vapor had a great influence on the density of $\bullet \mathrm{OH}$. When the content of water vapor in He was about $200 \mathrm{ppm}$, the concentration of $\bullet \mathrm{OH}$ was the largest and the oxidation rate was the highest. When the concentration of water vapor was greater than $200 \mathrm{ppm}$, the concentration of $\bullet \mathrm{OH}$ decreased with the increase in water vapor content. This was because at high water vapor content, the excited state of $\bullet \mathrm{OH}$ was effectively quenched, which greatly reduced its density. As shown in Figure 18, three types of step/terrace structure were produced after $4 \mathrm{H}-\mathrm{SiC}$ polished by the $\mathrm{CeO}_{2}$ slurry: $a-a, a-b$, and $a-b-a^{*}-b^{*}$. When the polishing rate $\left(R_{p}\right)$ was lower than the oxidation rate $\left(R_{o}\right)$, the $a-b-a^{*}-b^{*}$ type was generated (Figure 18a). When the polishing rate was comparable to the oxidation rate, the $a-b-a^{*}-b^{*}$ type changed to the $a-b$ type, as shown in Figure $18 b$. In the case of the polishing rate becoming greater than the oxidation rate, a uniform a-a type was generated [46] and the step height was $0.25 \mathrm{~nm}$ (Figure 18d).
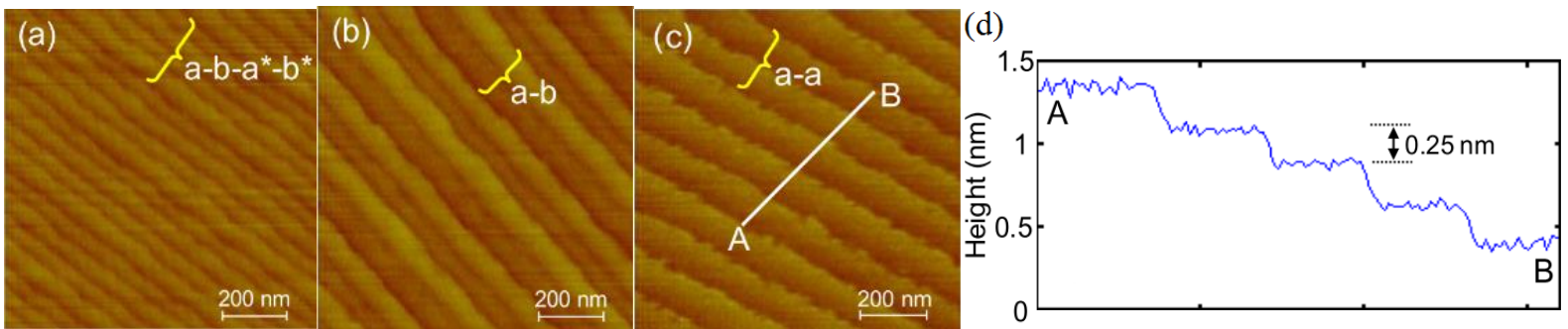

Figure 18. AFM images of the $\mathrm{SiC}$ surfaces processed by $\mathrm{CeO}_{2}$ abrasives: (a) $\mathrm{Rp}<\mathrm{Ro}$, (b) $\mathrm{Rp} \approx \mathrm{Ro}$, (c) $\mathrm{Rp}>\mathrm{Ro},(\mathbf{d})$ cross-sectional of $\mathrm{AB}$ in (c) [45].

To investigate the influence of surface defects on PAP, quantum chemistry simulation was used to analyze the interface reaction characteristics of single-crystal SiC in Jia's study [13]. The results showed that the surface defects can improve the MRR. In the initial polishing stage, surface defects did lead to poor surface roughness, but after most of the damage was removed, surface roughness can be effectively improved so that the final machining quality cannot be affected. 
The surface quality of single-crystal SiC obtained by PAP is high, while the MRR is low $(<0.2 \mu \mathrm{m} / \mathrm{h})$. Moreover, its process operation is poor due to the complex polishing system, plasma generation, and irradiation devices.

\subsection{Electrochemical Mechanical Polishing (ECMP)}

Figure 19 shows a typical setup of ECMP used for single-crystal SiC. ECMP is a precision technology that combines the low-voltage electrochemical corrosion of the workpiece with mechanical polishing by using electrolyte as the polishing slurry. An oxide layer on the single-crystal SiC (as the anode) surface is generated by anodic oxidation after charged, and then the oxide layer is mechanically removed by the soft abrasives. Finally, a smooth surface without SSD can be obtained.

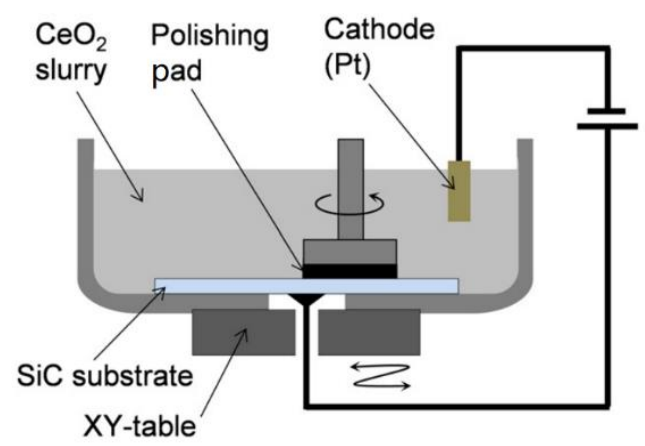

Figure 19. Schematic of ECMP setup [15].

To achieve a faster polishing rate with minimal damage to the SiC surface, ECMP using the slurry with $\mathrm{H}_{2} \mathrm{O}_{2}, \mathrm{KNO}_{3}$, and $\mathrm{SiO}_{2}$ abrasives was first applied to the precise polishing of single-crystal $\mathrm{SiC}$, which combined the anodic oxidation with conventional $\mathrm{CMP}$ by $\mathrm{Li}$ [47] in 2004. It was found that when the current density was in the range of $10 \mu \mathrm{A} / \mathrm{cm}^{2} \sim 20 \mathrm{~mA} / \mathrm{cm}^{2}$, the MRR increased with the increase in current density. When the current density was $1 \mathrm{~mA} / \mathrm{cm}^{2}$, the optimal surface with $\mathrm{Sq}=0.2 \mathrm{~nm}$ can be obtained, but the MRR was lower than $0.2 \mu \mathrm{m} / \mathrm{h}$. While the current density was $20 \mathrm{~mA} / \mathrm{cm}^{2}$, the MRR could reach a maximum value of $0.5 \mu \mathrm{m} / \mathrm{h}$, but the surface roughness (Sq) increased to $10.52 \mathrm{~nm}$. However, the excessive current density caused wavy pits after ECMP treatment, which increased the surface roughness. It is believed that the formation of pits was related to the distribution of the electric field on the workpiece surface during anodic oxidation. The field lines were concentrated at the surface "peaks" and selectively enhanced the anodization and removal of $\mathrm{SiC}$. At a low current density, the selective anodic oxidation and removal rate of silicon carbide were not high enough to form holes, so the surface roughness after mechanical polishing was low. However, a higher current density enhanced the nonuniformity of the surface breakdown, resulting in the formation of holes and higher surface roughness. To avoid scratches on the SiC surface, electrochemical corrosion and mechanical removal should be combined synergistically and efficiently. A Smooth SiC surface could be obtained by anodic oxidation and mechanical removal by the two-step process. However, the atomic roughness of the ECMP-polished surface could be achieved by high-temperature hydrogen etching. Controlling the balance between anodic oxidation and mechanical removal plays a key role in ECMP. A lot of efforts were put to this topic, such as using periodic bias and a more effective abrasive. Additionally, the corresponding mechanism was also explored.

Yamamura [48] conducted synchronous electrochemical mechanical polishing of $4 \mathrm{H}-$ $\mathrm{SiC}$ with $1 \mathrm{wt} \% \mathrm{H}_{3} \mathrm{PO}_{4}$ and deionized water as electrolytes and $\mathrm{CeO}_{2}$ polishing film as mechanical polishing media, respectively. The results showed that the surface roughness of $\mathrm{SiC}$ processed by ECMP depended on the relationship between the anodic oxidation rate and the mechanical removal rate. In case of the anodic oxidation rate bigger than the mechanical removal rate, the surface roughness was larger than that of the original SiC. 
When the mechanical removal rate was bigger than the anodic oxidation rate, the surface roughness was smaller than that of the original $\mathrm{SiC}$, but the MRR was very low. The essence was that the roughness of the SiC surface after ECMP was determined by the roughness of the oxide/SiC interface. The cross-sectional transmission electron microscope (XTEM) image of the anodized surface (Figure 20) showed that the roughness of the oxide/SiC interface increased due to the formation of egglike protrusions. Therefore, simultaneous removal of oxide by abrasive polishing before thick oxide formation was essential to obtain a smooth surface.

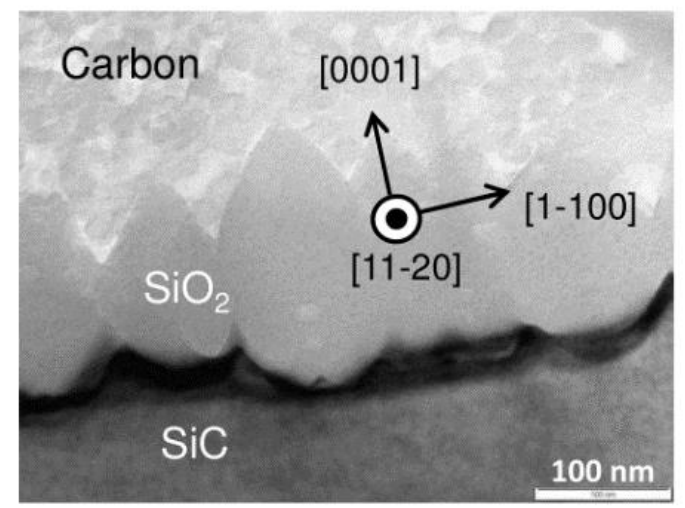

Figure 20. XTEM image of anodic oxidized 4H-SiC surface [48].

As shown in Figure 21a, a novel polishing slurry containing self-made $\mathrm{CeO}_{2}$-polyurethane(PU) core-shell particles and deionized water was used for electrochemical mechanical polishing of $4 \mathrm{H}-\mathrm{SiC}$ in Murata's report [49]. It was found that when continuous bias was applied, the scratches were easily introduced to the polished surface, and the surface roughness Ra increased from $4.38 \mathrm{~nm}$ to $6.61 \mathrm{~nm}$ owing to the oxide film remaining on the processed surface, which was caused by the higher oxidation rate than the oxide removal rate. On the other hand, a smooth surface can be obtained by applying periodic bias. Based on Faraday's law, an optimal electrolysis condition of $E=10 \mathrm{~V}, T_{\text {on }}: T_{\text {off }}=2.5 \mathrm{~min}: 7.5 \mathrm{~min}$ was obtained, as shown in Figure 21b. Under this condition, it was estimated that the oxide rate of $\mathrm{SiC}$ was $3.70 \mu \mathrm{m} / \mathrm{h}$, which was close to the removal rate of a soda lime glass by using $\mathrm{CeO}_{2} / \mathrm{PU}$ core-shell particles under the same condition, but the definite MRR was not given. The surface roughness Ra decreased from $5.43 \mathrm{~nm}$ to $0.51 \mathrm{~nm}$ after $90 \mathrm{~min}$ ECMP.

(a)

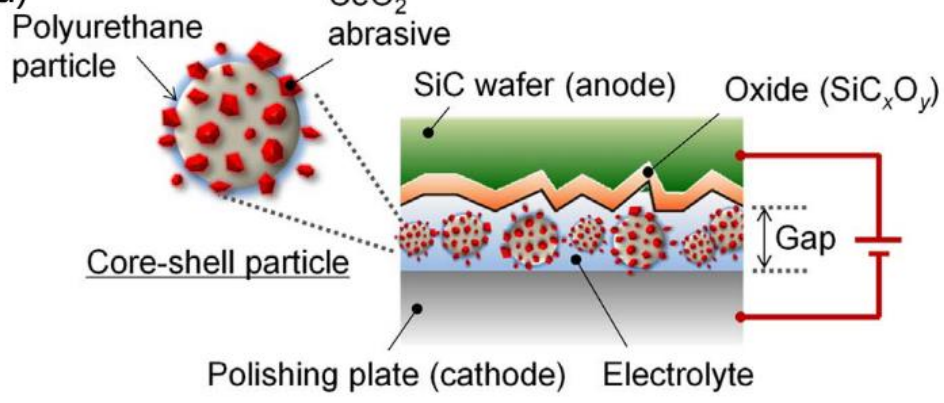

(b)

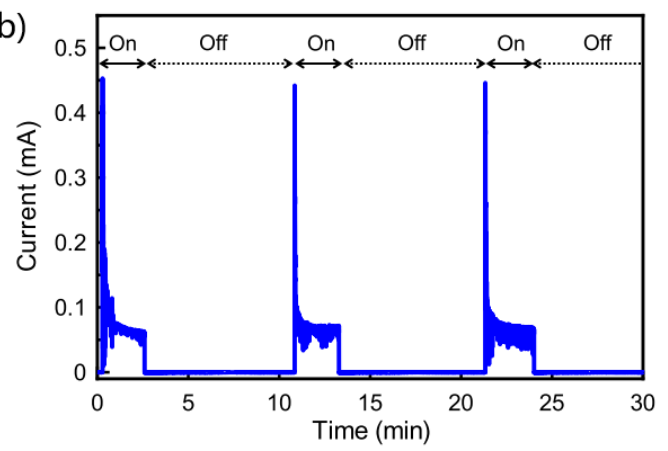

Figure 21. (a) Schematic view of the Murata-proposed ECMP method; (b) time dependence of anodic current during ECMP with a periodic bias [49].

Gao [50] studied the balance between the silicon carbide oxidation rate and the $\mathrm{SiO}_{2}$ layer removal rate in the ECMP of $4 \mathrm{H}-\mathrm{SiC}$. Based on the experimental data, the equations of the $\mathrm{SiC}$ corrosion rate and the $\mathrm{SiO}_{2}$ layer removal rate were obtained by the modified Preston's equation and Faraday's law, respectively. Finally, a verified test was conducted in the slurry containing $0.2 \mathrm{M} \mathrm{NaOH}$ electrolyte and $5.0 \mathrm{wt} \%$ polystyrene (PS) $/ \mathrm{CeO}_{2}$ 
abrasives. The results showed that if the $\mathrm{SiC}$ oxidation rate was higher than the $\mathrm{SiO}_{2}$ layer removal rate, a residual oxidation layer was left on the SiC surface, which resulted in many scratches. Besides, the polishing efficiency was too low. A balance of the oxidation rate and the mechanical removal rate can be reached under the condition of the current at $80 \mathrm{~mA}$, the rotation speed at $40 \mathrm{rpm}$, and the polishing pressure at $25 \mathrm{kPa}$. Under this condition, a smooth surface without scratches was obtained $(\mathrm{Ra}=0.449 \mathrm{~nm})$, and the MRR was up to $2.3 \mu \mathrm{m} / \mathrm{h}$.

Yang [51] studied the effect of the balance between the anodic oxidation rate and the oxide removal rate on the polishing performance of $4 \mathrm{H}-\mathrm{SiC}$ ECMP by the ceria grinding stone. It was found that with the increase in the oxide layer, the interface between $\mathrm{SiC}$ and the oxide layer became rough, which led to the increase in SiC surface roughness after ECMP. The surface roughness obtained by ECMP was mainly determined by the balance between the anodic oxidation rate and the oxide removal rate. Therefore, the oxide removal rate should be greater than the anodic oxidation rate to obtain a smooth surface. The surface roughness Sq of a diamond-lapped 4H-SiC (0001) surface was decreased from $4.290 \mathrm{~nm}$ to $0.577 \mathrm{~nm}$, and a high MRR of about $10 \mu \mathrm{m} / \mathrm{h}$ was obtained by ECMP for $30 \mathrm{~min}$ under a feed rate of $10 \mathrm{~mm} / \mathrm{s}$, a current density of $10 \mathrm{~mA} / \mathrm{cm}^{2}$, and a $\mathrm{NaCl}$ electrolyte of $1 \mathrm{wt} \%$.

Anodic oxidation was very effective in removing SiC surface damage caused by mechanical polishing. The surface after removing surface damage can be oxidized uniformly, and the oxidation rate was higher than that after chemical mechanical polishing [52]. Yang [16] used ECMP to flatten the sliced $4 \mathrm{H}-\mathrm{SiC}$ surface. Experimental results showed that the ceria grinding stone was the best choice for the overall polishing efficiency and polishing quality among the ceria grinding stone, the $\mathrm{Al}_{2} \mathrm{O}_{3}$ grinding stone, and the $\mathrm{SiO}_{2}$ grinding stone. An atomically smooth $\mathrm{SiC}$ surface without scratches and subsurface damages was obtained after the ECMP was processed for $2 \mathrm{~h}$ by the ceria grinding stone at a current density of $10 \mathrm{~mA} / \mathrm{cm}^{2}$ in $1 \mathrm{wt} \% \mathrm{NaCl}$ electrolyte. The surface roughness Sq decreased from $286 \mathrm{~nm}$ to $1.352 \mathrm{~nm}$, and the MRR was about $23 \mu \mathrm{m} / \mathrm{h}$. Results showed that the ECMP with the ceria grinding stone can be used to integrate the grinding and lapping processes and simplify the manufacturing process with a high MRR and a low cost.

To improve the surface roughness of 4H-SiC after ECMP, Murata [53] applied a periodic bias in ECMP by a Ce thin film with holes and obtained the optimal electrolytic parameter with a duty ratio $\left(T_{\text {on }}:\left(T_{\text {on }}+T_{\text {off }}\right)\right)$ of $45 \%$, a duty period $\left(T_{\text {on }}+T_{\text {off }}\right)$ of $10 \mathrm{~min}$, and an applied voltage of $10 \mathrm{~V}$. A smooth scratch-free surface with a roughness Ra of $0.49 \mathrm{~nm}$ was obtained after ECMP by the Ce thin film under the optimal electrolytic parameter. The ECMP using $\mathrm{CeO}_{2}$ abrasives was also conducted for comparison with the ECMP using a Ce thin film. It was found that the surface roughness of the ECMP using a thin film under the same conditions was much better than that of the ECMP using $\mathrm{CeO}_{2}$ abrasives, while the MRR was not as good as that of the latter, which was due to the difference in the oxide removal mechanism. As shown in Figure 22, the $\mathrm{CeO}_{2}$ particles in the ECMP contacted and removed the oxide scratches, resulting in wider scratches. Such scratch widening behavior in single-crystal $\mathrm{SiC}$ polishing using a $\mathrm{CeO}_{2}$ polishing slurry was also reported by Deng [54]. In contrast, only the oxide at the point where the film contacted can be removed in ECMP using a Ce thin film. Therefore, the scratch would not be widened during processing.

Deng [15] used the polishing slurry containing only $\mathrm{CeO}_{2}$ and deionized water to conduct synchronous electrochemical mechanical polishing of $4 \mathrm{H}-\mathrm{SiC}$. The results of nanoindentation in Figure 23a showed that the hardness of the oxide layer was $1.9 \mathrm{GPa}$, which was much less than the quartz glass $\left(\mathrm{SiO}_{2}\right)$ of $12 \mathrm{GPa}$ and the $\mathrm{SiC}$ of $34.5 \mathrm{GPa}$. From Figure $23 \mathrm{~b}$, it can be concluded that the ECMP was conducted on CMP-treated SiC and diamond-abrasive-polished $\mathrm{SiC}$ under the same conditions, and MRRs were $0.42 \mu \mathrm{m} / \mathrm{h}$ and $3.62 \mu \mathrm{m} / \mathrm{h}$, respectively. It thus appeared that the ECMP was more effective for SiC with scratches and subsurface damages. After the $\mathrm{SiC}$ surface was processed by the ECMP 
for $30 \mathrm{~min}$, a smooth surface without scratches and subsurface damage was obtained, and the $\mathrm{Sq}$ roughness decreased from $0.97 \mathrm{~nm}$ to $0.23 \mathrm{~nm}$.

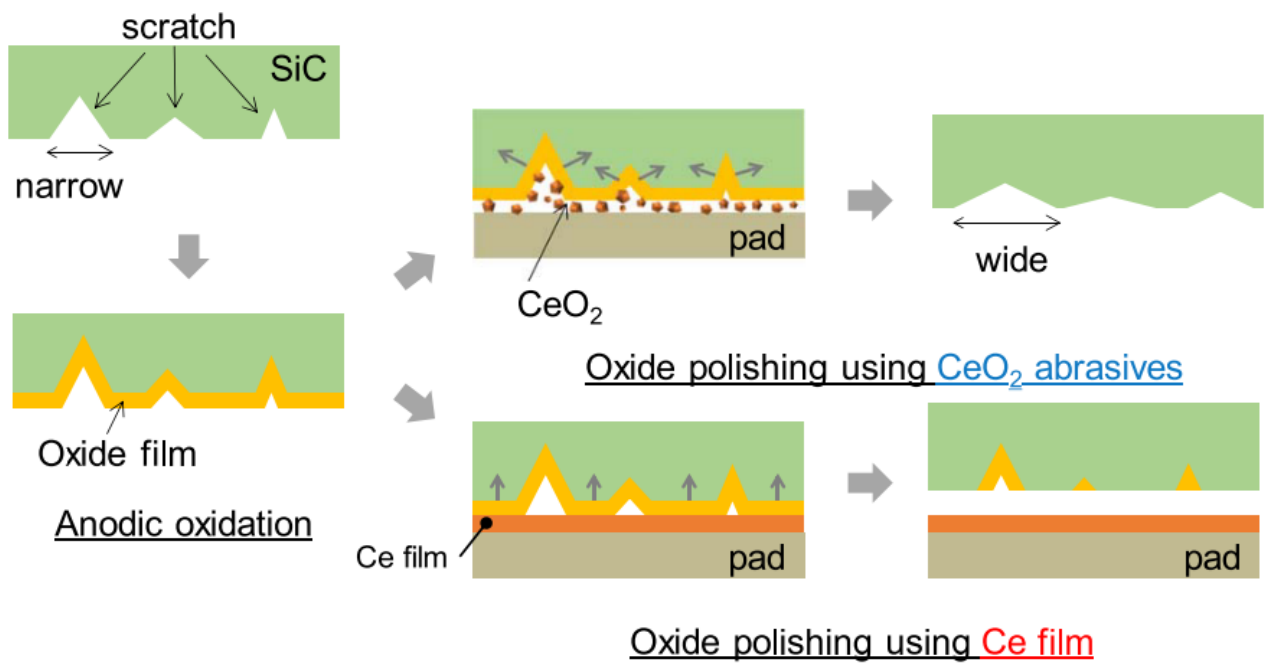

Figure 22. Schematic of the mechanism of $\mathrm{SiC}$ ECMP using $\mathrm{Ce}$ film and $\mathrm{CeO}_{2}$ abrasives [53].
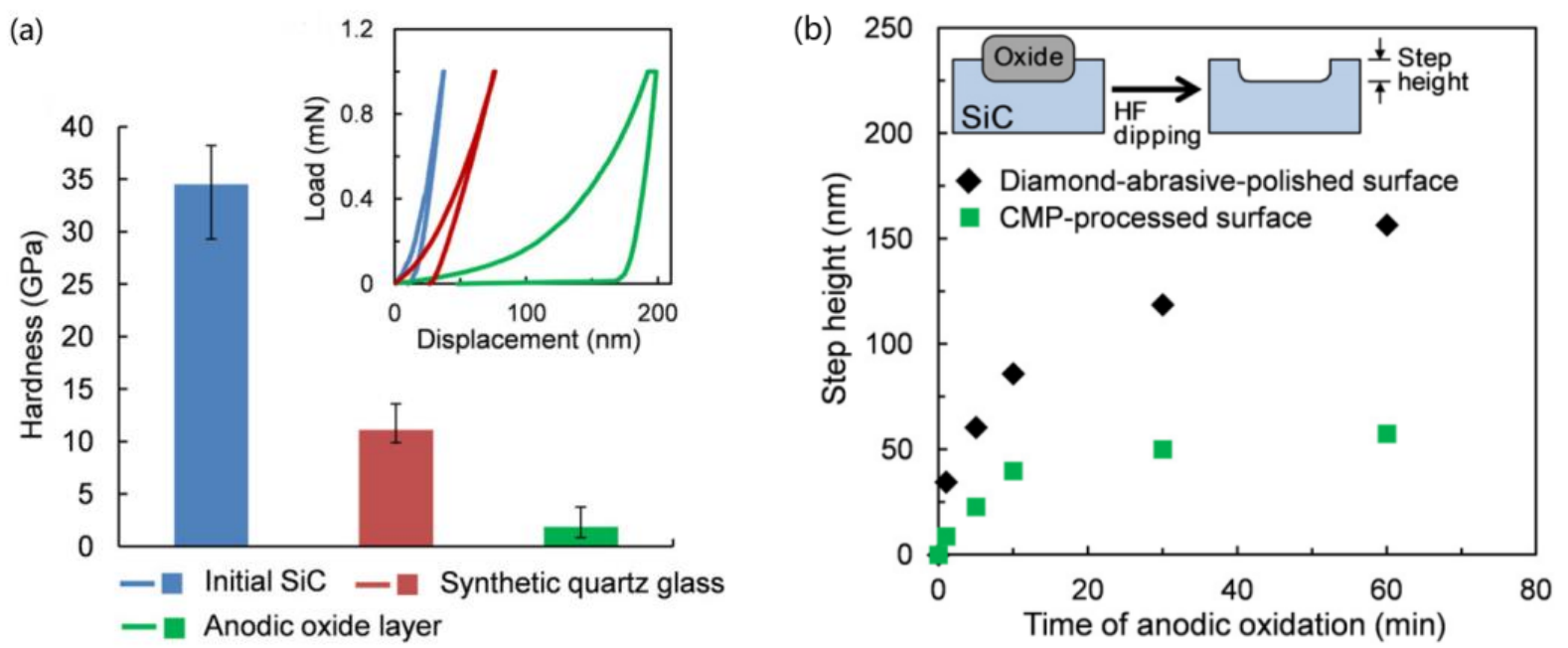

Figure 23. (a) Hardness measured by the nanoindentation method, (b) thickness of anodically oxidized $\mathrm{SiC}$ with different durations [15].

Liu [55] conducted an experimental study on the occurrence and development of local oxidation in the anodic oxidation of $4 \mathrm{H}-\mathrm{SiC}$ using a three-electrode system and the electrolyte of $\mathrm{KCl}$ solution. Since anodic oxidation was based on the transfer of electrons from the electrolyte to the electrolyte/silicon carbide interface, local oxidation preferentially occurred in the charge carrier- rich areas, such as damage and doping regions. It was found that the anodic oxidation had a high priority around the damaged areas. Along the scratched areas, a large amount of covalent bonds formed by carbon atoms and neighboring silicon atoms was broken, which led to the creation of a large number of dangling bonds, free electrons, and holes. Therefore, the scratch area had a high density of carriers, which greatly improved the conductivity of these areas. Anodic oxidation of the damage-free areas occurred randomly due to the random distribution of doping sites in the $\mathrm{SiC}$ wafer.

Yang [56] used AFM to study the characteristics of the $4 \mathrm{H}-\mathrm{SiC}$ surface at the initial anodic oxidation stage. Results showed that both the original surface (after CMP was processed) and the $\mathrm{SiC}$ surface during initial anodic oxidation presented a rough step/terrace structure, and the step height always remained at $0.25 \mathrm{~nm}$. Oxidation started from the edge 
of the terrace and extended to the bottom of the terrace. At the initial oxidation stage, a thin oxide layer of $\mathrm{SiC}_{\mathrm{x}} \mathrm{O}_{\mathrm{y}}$ was formed on the $\mathrm{SiC}$ surface. Subsequently, large oxide protrusions were generated, and pits were formed after the removal of protrusions, which increased the surface roughness greatly. Therefore, to get a smooth surface by ECMP, the oxide must be removed immediately before its expanding. Yang also found that there are five oxidation phases of $4 \mathrm{H}-\mathrm{SiC}$ anodic oxidation at different potentials, as shown in Figure 24 [57]:

(1) Unoxidized state (ab): the anodic oxidation did not occur since no current flowed;

(2) Active state (bc): the anodic oxidation began to occur when the voltage increased into the active stage;

(3) Passive state (cd): the oxidation reaction was hindered by the passive film due to the increase in the thickness of oxide film;

(4) Transient state (de): the oxide protrusions were generated by the breakdown of the passive film;

(5) Transpassive state (ef): as the voltage continued to rise, the current increased with the increasing of the voltage and entered into the transpassive state. The oxide protrusions were introduced between the transient state and the transpassive state.

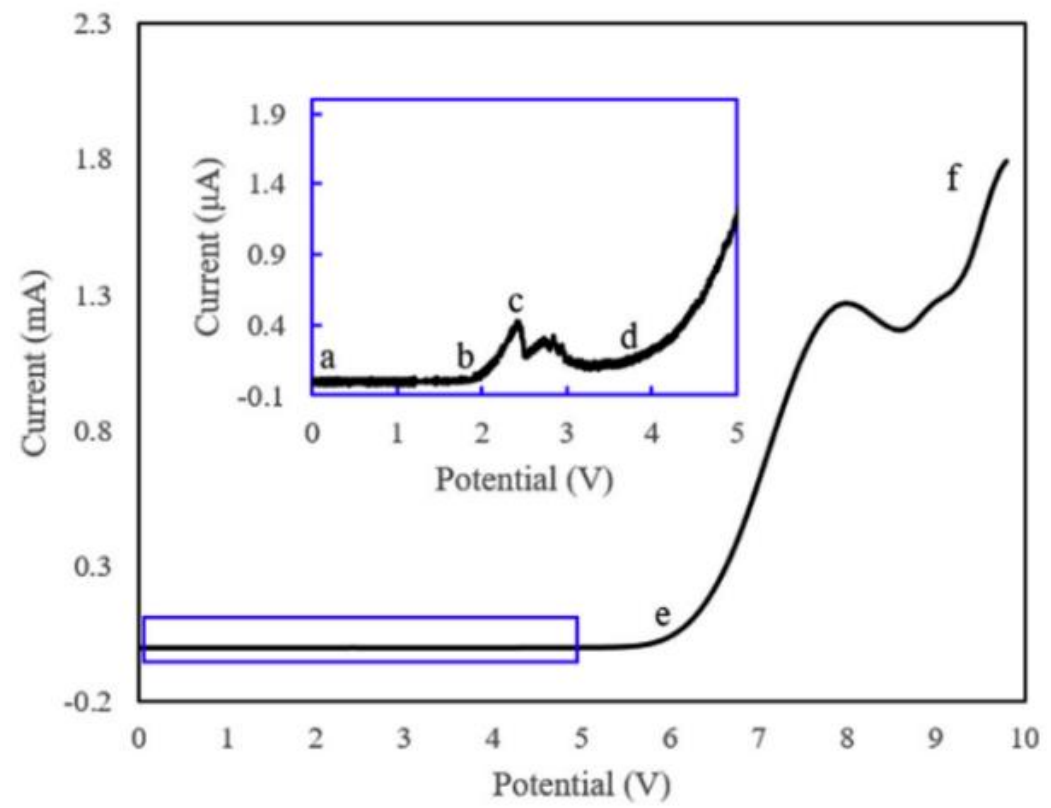

Figure 24. Linear scanning voltammetry (LSV) result for 4H-SiC [57].

The mode of the anodic oxidation process of the $4 \mathrm{H}-\mathrm{SiC}$ surface is shown in Figure 25. In the initial oxidation stage as shown in Figure 25b, the edges of the scratches and SSD were preferentially oxidized, while the remaining part of the surface was passivated. If the oxidation potential was insufficient to break down the passive film, the further oxidation of the surface was hindered by the passive film, and only scratches and SSD were oxidized. On the contrary, if the potential was sufficient, the passive film would be broken down at the atomic pits, and then the current was concentrated at the breakdown due to the low resistance, which resulted in the oxide protrusions (etching pits) as shown in Figure 25c. Anodic oxidation was the oxidation of $\mathrm{SiC}$ by the hydroxyl group in the electrolyte. In the initial stage, the diffusion of hydroxyl groups was not significantly hindered by the oxide protrusions with a relatively small thickness, so the longitudinal growth of pits occurred. In the late-growth stage, with the increasing thickness of the oxide protrusions, the diffusion of hydroxyl groups in the oxide layer became difficult, particularly at the center of the pits, and this resulted in the lateral growth of the pits. Therefore, for SiC's ECMP process, the surface damage layer should be completely removed by oxidation at a high oxidation rate 
first, and then the surface should be polished at a low potential in the passive stage to avoid the generation of etching pits so as to obtain an atomically smooth surface.

(a)

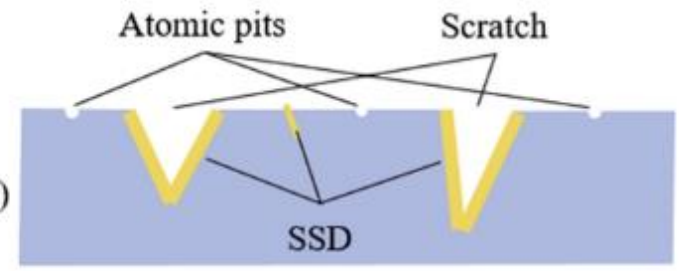

凸

Passive film Preferentially oxidation on SSD

(b)

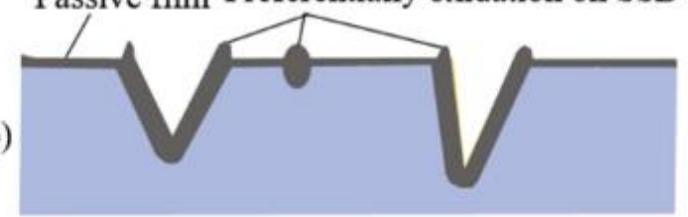

(d)
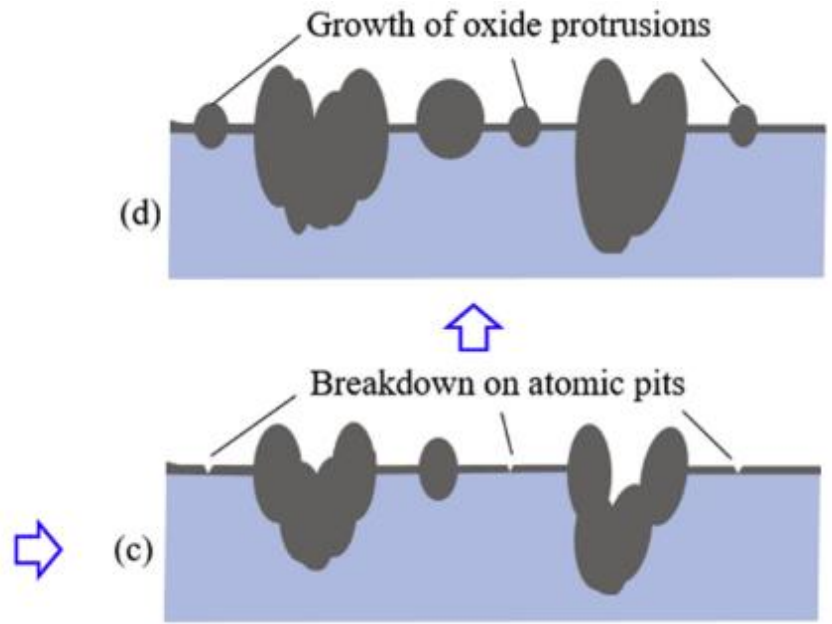

Figure 25. Modeling of the anodic oxidation process of the $4 \mathrm{H}-\mathrm{SiC}$ surface: (a) the original surface; (b) the initial stage of anodic oxidation; (c) the second stage of anodic oxidation; (d) the final stage of anodic oxidation [57].

A high MRR can be achieved by ECMP. In addition, it is an environmentally friendly precision polishing process for $\mathrm{SiC}$ owing to the neutral salt solution used as the electrolyte in ECMP. However, the formation of the egglike protrusions $[15,48]$ at the oxide/SiC interface during anodic oxidation would lead to a bigger surface roughness after ECMP than that of PAP.

\subsection{Catalyst-Referred Etching (CARE)}

Catalyst-referred etching is a polishing technique that uses a metal catalyst to accelerate the chemical dissolution of single-crystal $\mathrm{SiC}$ in the absence of abrasive conditions, while the metal is used as a polishing disc to smooth-polish single-crystal SiC. Figure 26 shows a typical schematic of a CARE system for single-crystal SiC. In CARE, the etching reaction only occurs at the catalyst surface. Because the surface of the catalyst plate serves as a reference surface, the protrusions on the substrate surface are etched selectively. For planarization of a $\mathrm{SiC}$ substrate using CARE, platinum and hydrofluoric acid serve as the catalyst and the processing solution, respectively.

\section{Wafer holder}

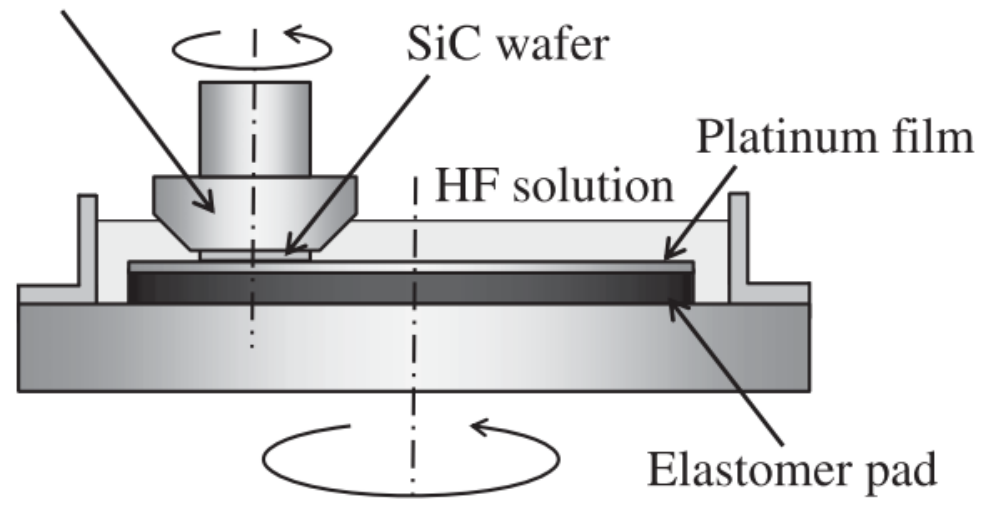

Figure 26. Schematic of CARE system for single-crystal SiC [58]. 
In 2006, Hideyuki Hara [17] et al. proposed the method of catalyst-referred etching (CARE) to polish a $4 \mathrm{H}-\mathrm{SiC}$ (0001) surface. The polishing pad made of $\mathrm{Pt}$ was fixed on the rotating table and rotated with the rotating table. The single-crystal $\mathrm{SiC}$ wafer was attached to the polishing head and pressed on the polishing pad at a certain pressure (less than the pressure of the traditional polishing process). Different from the traditional polishing process, abrasive particles were not required in the CARE process $[59,60]$. The material removal mechanism of CARE was that hydrofluoric acid (HF) was activated as an etching agent under the action of a Pt catalyst to preferentially remove the convex peaks on the single-crystal SiC surface. As shown in Figure 27, compared with CMP, CARE produced almost no scratches on the polished single-crystal $\mathrm{SiC}$ surface due to the lower pressure applied. The surface roughness $(\mathrm{Ra})$ can reach $0.1 \mathrm{~nm}$, and the material removal rate can reach $0.1-0.2 \mu \mathrm{m} / \mathrm{h}$.
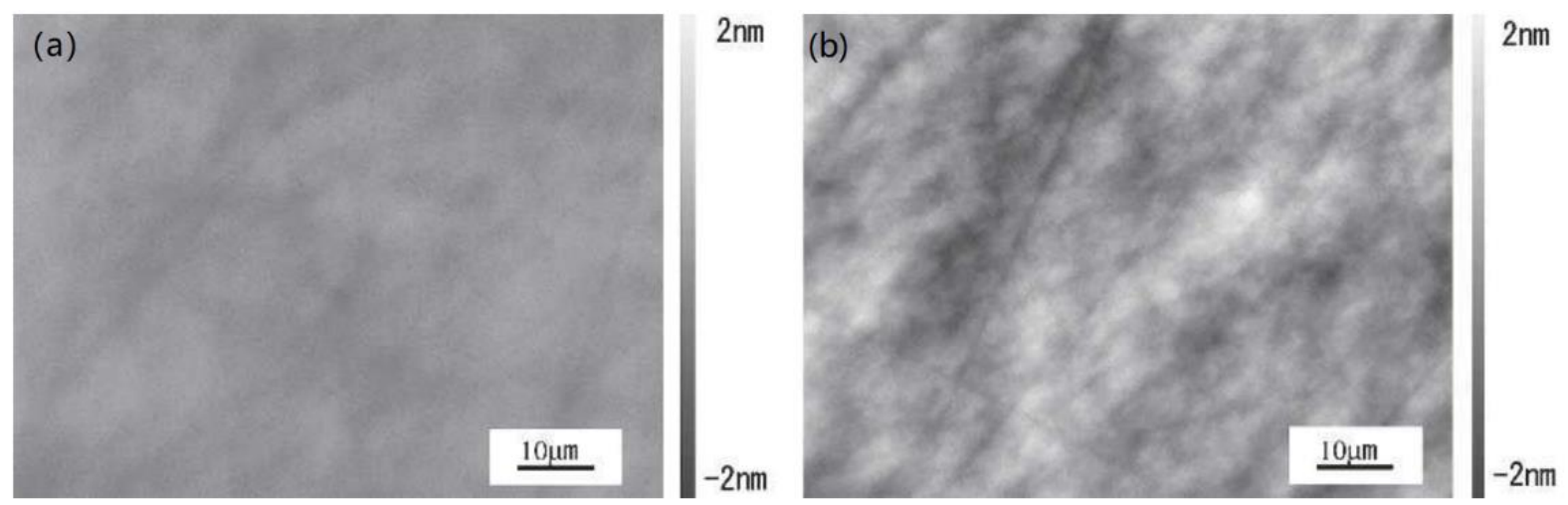

Figure 27. Optical interferometer images of a $4 \mathrm{H}-\mathrm{SiC}$ wafer: (a) CARE-processed surface Ra: $0.114 \mathrm{~nm}$, (b) as-received (after CMP) surface Ra: $0.436 \mathrm{~nm}[17]$.

In addition to HF, Keita Yagi et al. [61] found that the oxide could be dissolved by immersing a 2-inch $4 \mathrm{H}$-sic (0001) single wafer in ferrous sulfate $\left(\mathrm{FeSO}_{4}\right)$ and hydrogen peroxide $\left(\mathrm{H}_{2} \mathrm{O}_{2}\right)$ after oxidizing for $3 \mathrm{~h}$ and then immersing it in potassium hydroxide $(\mathrm{KOH})$ solution. The oxidation process was that single-crystal $\mathrm{SiC}$ was oxidized by the hydroxyl radical $(\bullet \mathrm{OH})$ produced by the reaction of $\mathrm{Fe}^{2+}$ with $\mathrm{H}_{2} \mathrm{O}_{2}$ (Fenton reaction). Although atomically smooth surface morphology was obtained, the material removal rate was less than $30 \mathrm{~nm} / \mathrm{h}$. In 2008, Akihisa Kubota et al. [62] directly contacted Fe with a $4 \mathrm{H}-$ $\mathrm{SiC}$ (0001) surface in an $\mathrm{H}_{2} \mathrm{O}_{2}$ environment. At this time, Fe was used as both a catalyst to produce $\bullet \mathrm{OH}$ and a polishing pad to produce friction with single-crystal SiC. Experimental results showed that the removal characteristics of single-crystal $\mathrm{SiC}$ substrates depended on polishing time, rotating speed, contact load, and $\mathrm{H}_{2} \mathrm{O}_{2}$ concentration. Additionally, their relationship can be seen in Figure 28. The surface Sq of single-crystal SiC after polishing in this way could reach $0.1 \mathrm{~nm}$. In order to improve the material removal rate of CARE, Takeshi Okamoto et al. [58] studied the relationship between rotation speed and processing pressure on the material removal rate. The experimental results showed that the material removal rate of CARE polishing the 2 -inch $4 \mathrm{H}-\mathrm{SiC}$ (0001) surface was proportional to the rotation speed and polishing pressure, and a material removal rate of $500 \mathrm{~nm} / \mathrm{h}$ could be achieved by increasing the rotation speed and polishing pressure, and the root mean square roughness of polished single-crystal $\mathrm{SiC}$ was less than $0.1 \mathrm{~nm}$. The HRTEM image of a CARE-processed 4H-SiC surface (Figure 29) shows that the surface crystal structure was well ordered up to the topmost surface, and the processed surface had a step/terrace structure with a single-bilayer-step height. 
(a)

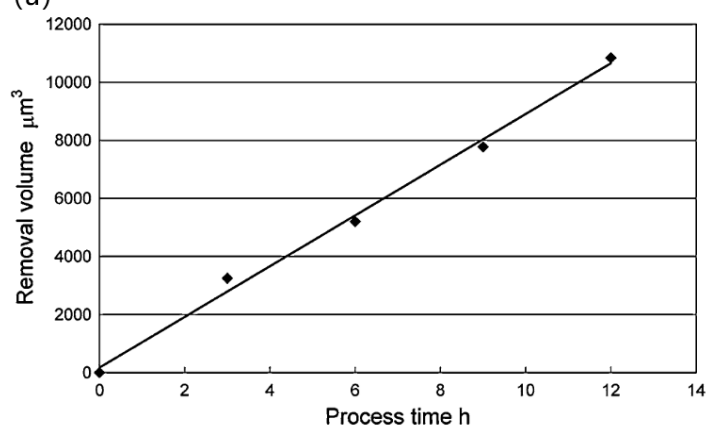

(c)

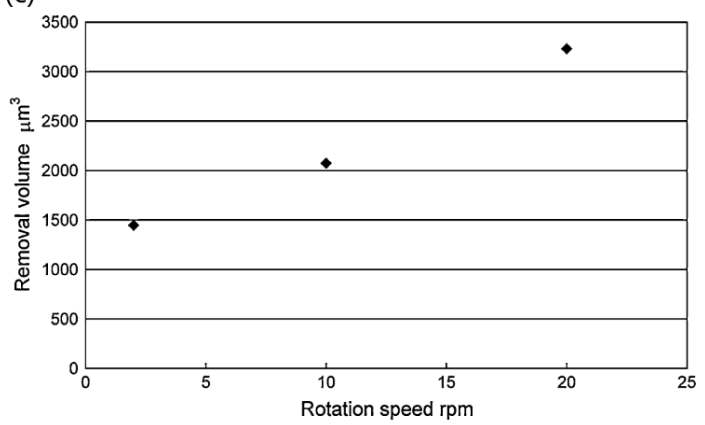

(b)

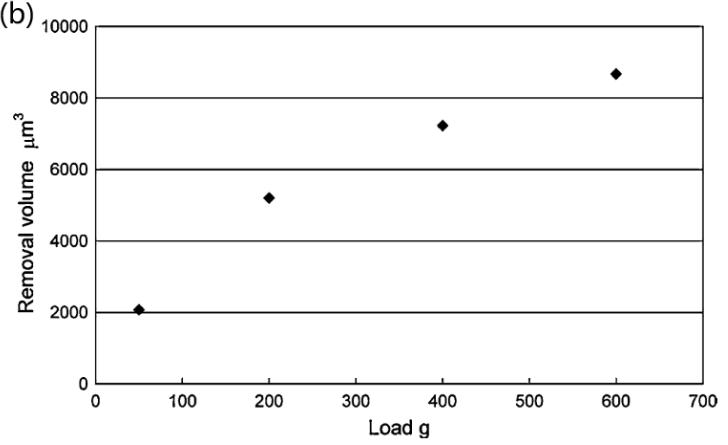

(d)

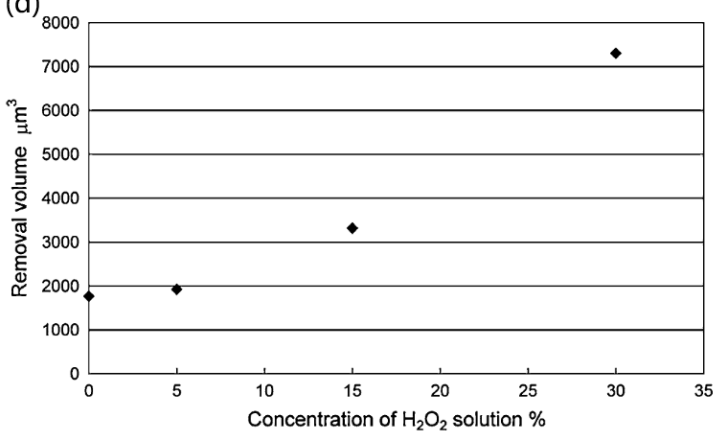

Figure 28. Relationship between removal volume and (a) process time, (b) contact load, (c) rotation speed, and (d) concentration of $\mathrm{H}_{2} \mathrm{O}_{2}$ solution [62].

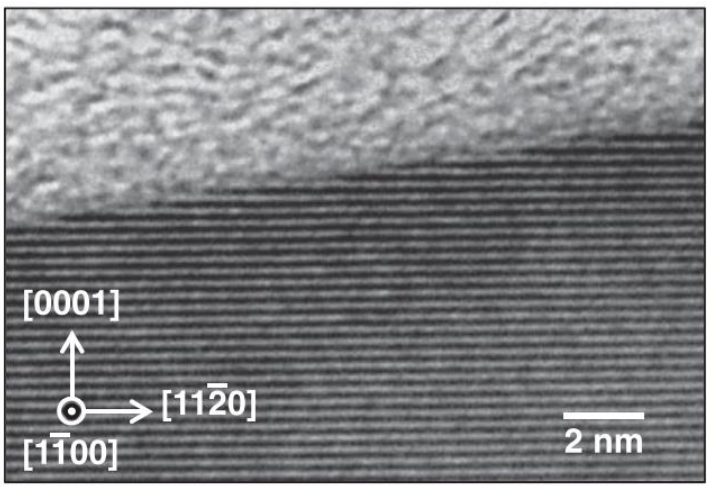

Figure 29. High-resolution TEM image of a CARE-processed 4H-SiC surface [58].

In early CARE studies, the catalyzed liquid medium was either $\mathrm{HF}$ or $\mathrm{H}_{2} \mathrm{O}_{2}$, which would cause adverse effects on the environment. In 2017, Ai Isohashi et al. [63] found that a 3-inch $4 \mathrm{H}-\mathrm{SiC}$ (0001) surface could still be polished in pure water under the action of a Pt catalyst with a certain electrochemical potential, and the etching mechanism was accelerated by hydrolysis under the action of $\mathrm{Pt}$. In the study, $\mathrm{OH}^{-}$is considered to play the same role as $\mathrm{F}^{-}$in CARE, as shown in Figure $30 \mathrm{~b}$, and to proceed with an indirect dissociative adsorption of $\mathrm{H}_{2} \mathrm{O}$ (i.e., indirect hydrolysis). Although etching could still occur in pure water, the material removal rate was more than 10 times lower than that of an HF solution, mainly because the ionization degree of water molecules was much lower than that of HF and the bond energy of Si-F (540-570 kJ/mol) was higher than that of Si-O (370-450 kJ/mol). The dependence of MRR upon the electrochemical potential of $\mathrm{Pt}$ was examined and is summarized in Figure 30c. It can be seen that the MRR can be improved by controlling the electrochemical potential of $\mathrm{Pt}$ to an oxidation condition. Pho Van Bui et al. [64] studied the reaction mechanism of a Pt catalyst on single-crystal $\mathrm{SiC}$ etching in water by density functional theory. The results showed that the etching of single-crystal $\mathrm{SiC}$ in water was produced by hydrolysis reaction, which destroyed the top 
layer of the Si-C bond. In addition, T. Okamoto et al. [65] processed the 2-inch 4H-SiC (0001) surface by CARE and manufactured an epitaxial layer on its surface, and then removed the surface roughness of the epitaxial wafer and finally manufactured the Schottky diode. Zhou [66] reported that an Fe catalyst was more preferable to 6H-SiC's CMP than that of $\mathrm{Pt} / \mathrm{C}$ nanoparticles. It was because the slurry with an Fe catalyst could produce more $\bullet \mathrm{OH}$, which can oxidize $\mathrm{SiC}$, while a $\mathrm{Pt} / \mathrm{C}$ catalyst caused an excessive decomposition of $\mathrm{H}_{2} \mathrm{O}_{2}$ into $\mathrm{H}_{2} \mathrm{O}$ and $\mathrm{O}_{2}$. A smooth defect-free surface with an atomic step/terrace structure and an extremely low Ra of about $0.05 \mathrm{~nm}$ was achieved for $6 \mathrm{H}-\mathrm{SiC}^{\prime} \mathrm{s} \mathrm{CMP}$ by using an $\mathrm{Fe}$ catalyst slurry, which contains $5 \mathrm{wt} \% \mathrm{H}_{2} \mathrm{O}_{2}, 0.3 \mathrm{wt} \% \mathrm{KOH}$, and $25 \mathrm{wt} \%$ colloidal silica.

(a)<smiles>C[Si](C)(O)OP</smiles>

(b) Pt Pt Pt Pt<smiles>C[Si](C)(O)O</smiles><smiles>C[Si](C)(F)OPC(=O)I</smiles><smiles>CCCCC</smiles>

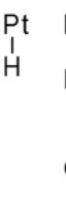<smiles>CCPO[Si](C)(C)F</smiles><smiles>CCPO[Si](C)(C)O[Tl]</smiles>

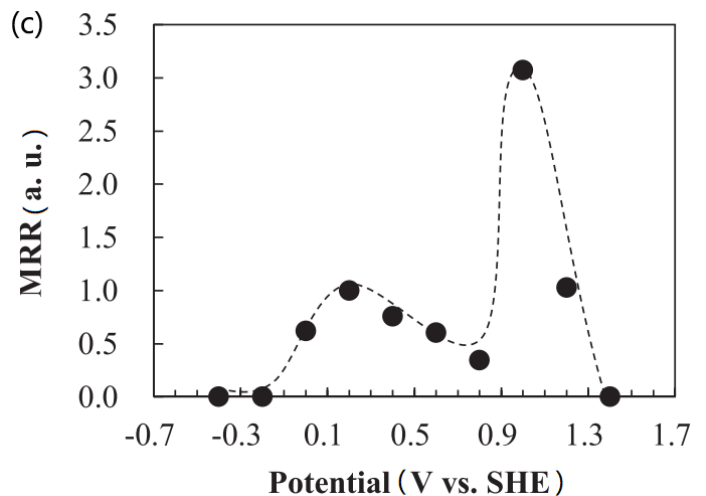

Figure 30. (a) Schematic of possible reaction pathways of (a) CARE with HF and (b) CARE with pure water; (c) dependence of relative MRR upon Pt potential [63].

An ultrasmooth defect-free single-crystal SiC surface with an atomic step/terrace structure can be obtained by CARE, and abrasive particles were not required in CARE processing, but the MRR was extremely low. An HF solution was toxic, and Pt was particularly expensive. If HF was replaced with pure water, a low voltage needed to be applied to the polishing system.

\section{Comparison of the Main Precision Polishing Technologies}

\subsection{Experimental Setup}

Figure 31 shows a schematic diagram of typical experimental setups of CMP, PCMP, PAP, and ECMP. It can be seen that the experimental setup of CMP (Figure 31a) is the simplest and easiest one to realize. While the polishing slurry usually contains acid or alkali, the strong oxidants and other environmentally harmful substances make it difficult and costly to dispose of the slurry after use. The $\mathrm{TiO}_{2}$ photocatalyst and UV irradiation devices are necessary for PCMP (Figure 31b), resulting in a more difficult implementation than CMP. However, the waste slurry will not harm human health and the environment owing to the nontoxicity of the $\mathrm{TiO}_{2}$ photocatalyst particles, and it has a certain capacity of sewage because of the strong oxidizing $\bullet \mathrm{OH}$. The experimental setup of PAP (Figure 31c) requires a complex plasma generation and irradiation device, which leads to poor operability. Figure 31d shows the experimental setup of ECMP, which has an additional electrical system compared with CMP. However, it is more environmentally friendly due to the selectivity of a neutral salt solution as the electrolyte of ECMP. Figure 31e shows the experimental setup of CARE. The HF solution was usually used as an etching solution, and Pt was usually used as a catalyst. The HF solution was toxic and Pt was particularly expensive, but abrasive particles were not required in CARE processing. If HF was replaced by pure water, a low voltage needed to be applied to the polishing system. 

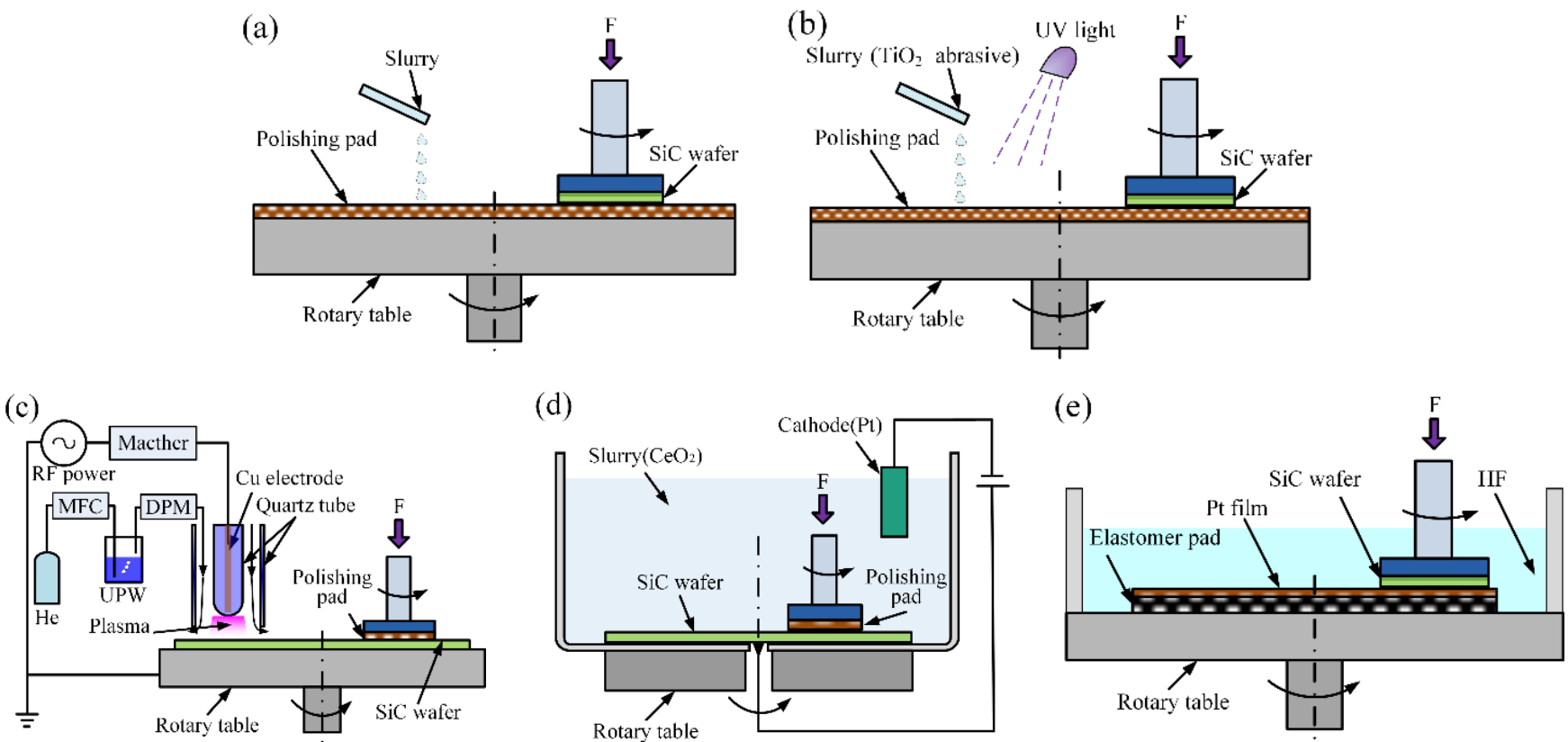

Figure 31. Schematic of the different experimental setups: (a) CMP [21], (b) PCMP [14], (c) PAP [38], (d) ECMP [15], and (e) CARE [58].

\subsection{Material Removal Rate (MRR) and Surface Roughness}

How to obtain a smooth surface with high efficiency is a key point in the semiconductor industry. Therefore, the MRR and the surface roughness are considered to be the two most important indexes to evaluate the quality of the single-crystal $\mathrm{SiC}$ polishing process. The maximum and minimum values of Ra and MRR for each technology from the literature are summarized in Table 2.

Table 2. MRR and Ra from the literature.

\begin{tabular}{|c|c|c|c|c|c|}
\hline \multirow{2}{*}{$\begin{array}{l}\text { Polishing } \\
\text { Technologies }\end{array}$} & \multicolumn{2}{|c|}{$\mathrm{Ra}(\mathrm{nm})$} & \multicolumn{2}{|c|}{$\operatorname{MRR}(\mu \mathrm{m} / \mathrm{h})$} & \multirow{2}{*}{ Remark } \\
\hline & Max & Min & Max & Min & \\
\hline $\mathrm{CMP}$ & 0.52 [27] & 0.108 [28] & $1.3[31]$ & $0.32[26]$ & (a) \\
\hline PCMP & $0.915[36]$ & 0.35 [14] & 0.95 [14] & 0.115 [36] & \\
\hline PAP & 0.2 [39] & $0.06[38]$ & 0.185 [42] & 0.08 [40] & \\
\hline ECMP & 0.51 [49] & $0.23[15]$ & $3.62[15]$ & $2.3[53]$ & (b) \\
\hline CARE & 0.1 [61] & $0.05[66]$ & 0.5 [58] & $0.03[62]$ & \\
\hline
\end{tabular}

Remark: (a) Both the MRR and Ra in Zhou and Pan's research studies [10,29] are the lowest, so they are not used as references. (b) Both the MRR and Ra in Li's research studies [47] are the lowest, and the MRR and Ra in Yang's research studies $[16,54]$ are the biggest, so they are not used as references.

The Ra vs. MRR of each polishing technology based on the data in Table 1 is shown in Figure 32. It can be seen that the best surface roughness with the lowest MRR can be realized by PAP and CARE. The highest MRR can be obtained by ECMP, but the surface quality is much lower than that of PAP, even worse than that of CMP. Since the mechanical process only removes the oxide layer and does not damage the substrate, the roughness of the $\mathrm{SiC}$ surface after polishing is determined by the oxide/ $\mathrm{SiC}$ interface. As shown in the XTEM image of the surface after oxidation (Figure 33), the interface between the oxide layer generated by plasma oxidation and $\mathrm{SiC}$ is very flat, resulting in a lower surface roughness $[39,40,42]$. On the other hand, the surface roughness after ECMP is processed is not as low as that of PAP due to the formation of the egglike protrusions generated at the oxide/SiC interface by anodic oxidation $[15,48]$. The MRR and Ra of PCMP are inferior to that of CMP. 


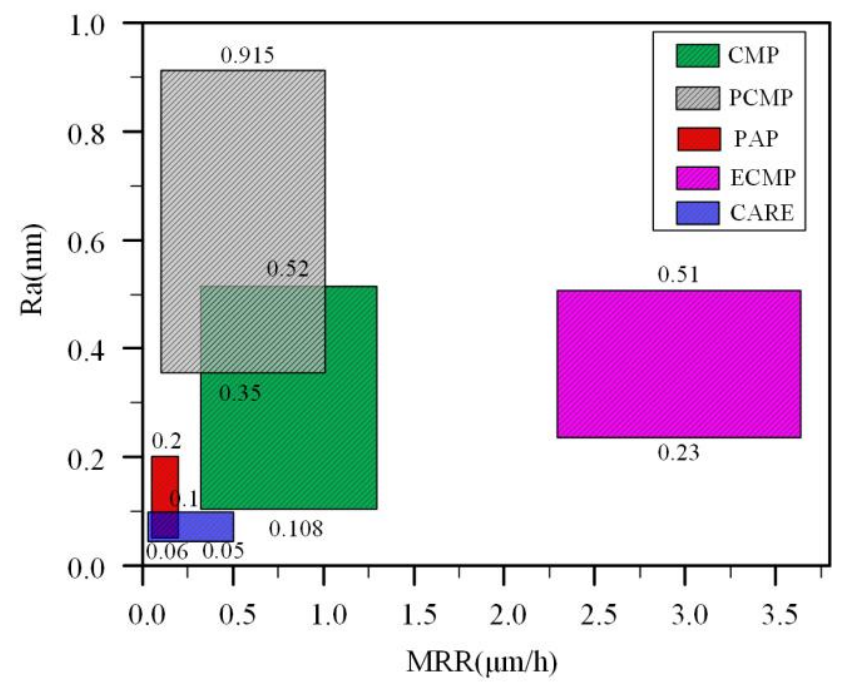

Figure 32. Ra vs. MRR of different polishing techniques.
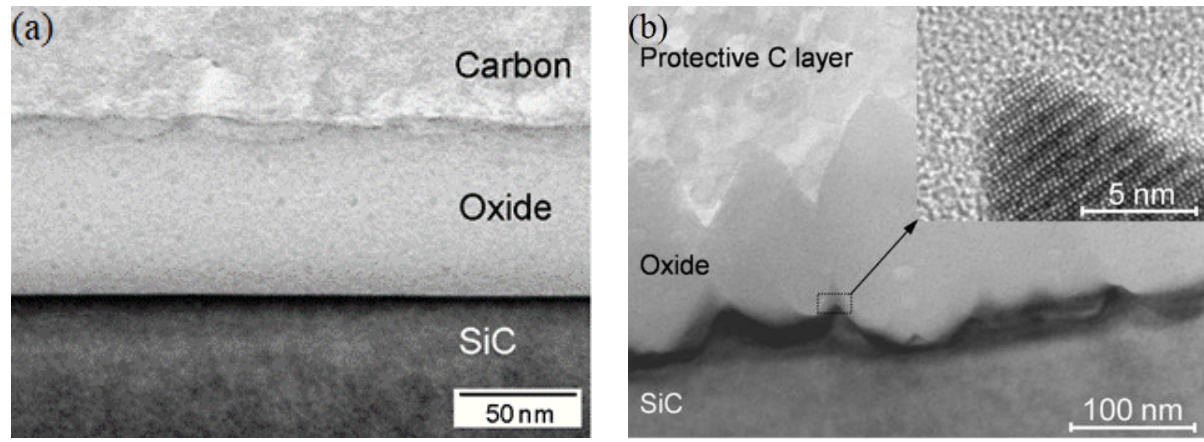

Figure 33. XTEM image of the surface after oxidation: (a) PAP [40], (b) anodic oxidation [15].

Comparisons of different polishing technologies for single-crystal $\mathrm{SiC}$ are summarized in Table 3. CMP is still commonly used for precision polishing of single-crystal SiC in industrial production, considering the feasibility of the ecological level, energy consumption, controllability, MRR, and surface quality comprehensively.

Table 3. Comparison of different polishing technologies for single-crystal SiC.

\begin{tabular}{|c|c|c|c|c|c|}
\hline $\begin{array}{l}\text { Polishing } \\
\text { Technologies }\end{array}$ & CMP & РCMP & PAP & ECMP & CARE \\
\hline Mechanism & $\begin{array}{c}\text { Chemical } \\
\text { oxidation }+ \\
\text { abrasive polishing }\end{array}$ & $\begin{array}{c}\text { Photocatalytic } \\
\text { oxidation }+ \\
\text { abrasive polishing }\end{array}$ & $\begin{array}{c}\text { Atmospheric } \\
\text { plasma oxidation }+ \\
\text { abrasive polishing }\end{array}$ & $\begin{array}{c}\text { Electrochemical } \\
\text { oxidation }+ \text { abrasive } \\
\text { polishing }\end{array}$ & $\begin{array}{l}\text { Chemical } \\
\text { dissolution }\end{array}$ \\
\hline MRR & Medium & Medium & Low & High & Low \\
\hline $\mathrm{Ra}$ & Medium & Medium & Low & High & Low \\
\hline Ecological level & Low & High & Medium & High & Low \\
\hline $\begin{array}{c}\text { Energy } \\
\text { consumption }\end{array}$ & Low & Medium & High & High & Low \\
\hline Controllability & High & Medium & Low & Low & Medium \\
\hline
\end{tabular}

\section{Other Probable Enhancement Polishing Technologies for Single-Crystal SiC}

CMP is the main industrial production technology for the precision polishing of singlecrystal $\mathrm{SiC}$ at present. However, the fabrication cost is too high due to its insufficient MRR and difficulty in waste slurry treatment, so current research studies are still focused on the development of a polishing technology to improve the MRR and surface quality. Ultrasonic 
wave has been widely used to improve the surface quality and production efficiency in recent years due to its specific ultrasonic effect (mechanical effect, cavitation effect, etc.). Electrolyte plasma polishing is a new environmentally friendly efficient polishing technology used in the precision polishing of a metal workpiece at present.

\subsection{Ultrasonic Vibration-Assisted Polishing}

It was reported that ultrasonic vibration-assisted polishing was an economical and effective polishing technology to improve the polishing performance of single-crystal $\mathrm{SiC}$.

Zhao [67] introduced ultrasonic vibration to abrasive polishing (AP) of $\mathrm{SiC}$ to improve the machining efficiency and surface quality. The experimental results showed that when the ultrasonic vibration was applied, the friction and friction coefficient were decreased, and the lubrication between the $\mathrm{SiC}$ surface and the polishing wheel was closer to the film lubrication state, thus improving the surface quality. The introduction of ultrasonic vibration could contribute to change the stress and temperature of the SiC surface, thus accelerating the formation of an $\mathrm{SiO}_{2}$ oxide layer, which was conducive to the improvement of the MRR.

A novel technology that combined ultrasonic CMP with ultrasonic grinding to improve the machining performance of $\mathrm{SiC}$ was reported by $\mathrm{Hu}$ [68]. It was found that ultrasonic grinding was beneficial to improve the MRR of CMP. Compared with conventional CMP, a higher MRR and a lower peak-to-valley (PV) roughness could be obtained by ultrasonic CMP. The results showed that the combination of ultrasonic CMP and ultrasonic grinding was a feasible technology to improve the grinding efficiency and surface quality of SiC.

Yang [69] proposed an ultrasonic-assisted electrochemical mechanical polishing (UAECMP) technology, which combined ultrasonic vibration with ECMP. The effect of ultrasonic vibration on the anodic oxidation rate of a $4 \mathrm{H}-\mathrm{SiC}$ (0001) surface was studied. Compared with conventional anodic oxidation, the oxidation rate increased by approximately $34 \%$ in the initial oxidation stage and about $11 \%$ in the subsequent anodic oxidation stage. Under ultrasonic vibration, the tiny bubbles in the electrolyte oscillated violently and increased in size. These bubbles expanded rapidly and collapsed when the sound pressure reached a certain threshold. This phenomenon is known as ultrasonic cavitation. During the cavitation process, intense heating of the bubbles occurred. These localized hot spots had extremely high temperature and pressure and were accompanied within a few microseconds by the formation of hydroxyl radicals, which played a key role in anodic oxidation [70,71]. The formation of transient high pressure and hydroxyl radical and the enhancement of electrolyte fluidity induced by the ultrasonic effect might promote the anodic oxidation rate of SiC. SEM images of the surface after anodic oxidation showed that UA could enhance the porosity of the oxide structure and increase the shedding rate of the oxide layer. The porosity of the oxide layer enabled hydroxyl radicals to react with the surface of SiC through the oxide layer, thereby increasing the oxidation rate. The porous structure of the oxide and the shedding of the oxide layer improved the subsequent mechanical removal rate of the oxide layer.

\subsection{Electrolyte Plasma Polishing (EPP)}

EPP is a special electrochemical polishing process under the condition of high voltage and environmental saline solution. It is an innovative polishing technology that can make the metal surface smooth and shiny in a short time and obtain a better corrosion resistance [72-74].

Figure 34 shows a schematic diagram of the electrolyte plasma polishing system, which consists of a power supply, electrolyte, cathode, workpiece anode, and insulated electrolytic cell. When the system was charged, the instantaneous short circuit of the system resulted in the evaporation of the electrolyte at the position contacting the workpiece, which generated a gas layer composed of water vapor to wrap around the workpiece and isolated the workpiece from the electrolyte [75-77]. Under the high electric field, electrons at the interface between the electrolyte and the gas layer were instantly accelerated to 
obtain enough speed and energy to rush to the surface of the workpiece. Then, the electrons directly collided with the water vapor molecules in the gas layer and released other electrons. These electrons struck other molecules, forming some form of electron avalanches. Then, the flow of electrons and ions formed a conductive channel, which connected the surface of the workpiece to the electrolyte. The channel was filled with high-temperature plasma, which is called plasma gas layer [78,79]. This process also brought about complex physicochemical effects, including ultraviolet light, shockwave, and ultrasonic cavitation. Active substances such as hydroxyl $\operatorname{radical}(\bullet \mathrm{OH})$, oxygen $\operatorname{radical}(\bullet \mathrm{O})$, hydroperoxide radical $\left(\bullet \mathrm{HO}_{2}\right), \bullet \mathrm{H}_{2} \mathrm{O}_{2}$, and $\bullet \mathrm{O}_{3}$ were produced by chemical effects $[80,81]$. Through the discharge channel, these active substances bombarded the surface of the workpiece and reacted with the workpiece to form an oxide film. The electrons moving in the opposite direction at a high speed in the discharge channel collided with the positive ions, leading to the bubble explosion. The plasma-gas layer had a different thickness on the peaks and in the cavities of the workpiece surface, leading to a higher current density on the peaks and, consequently, to a higher removal rate. The higher removal rate of the peaks led to a smoothing effect rapidly $[77,78]$.

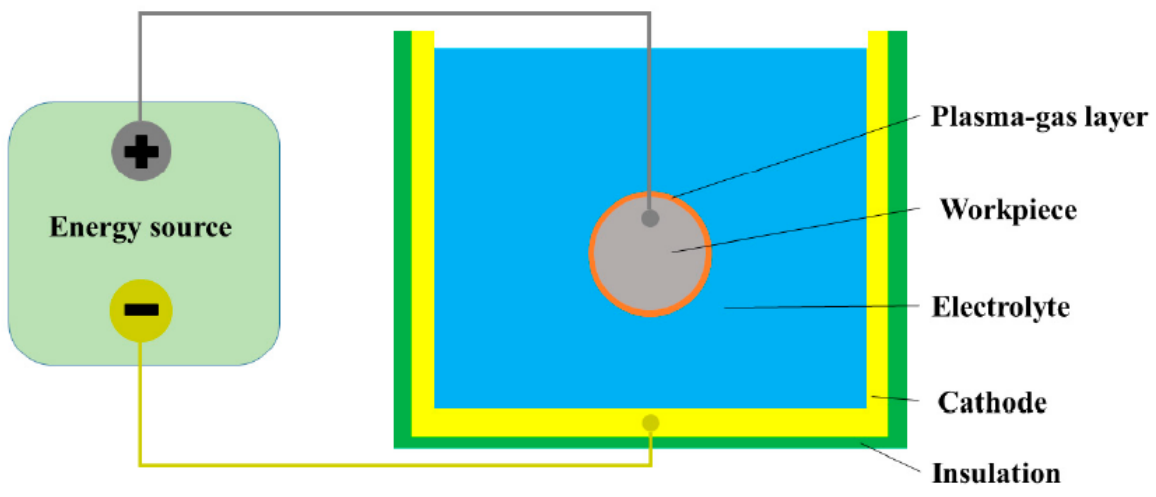

Figure 34. Schematic diagram of the electrolyte plasma polishing system [74].

In recent years, the application of EPP in a metal field has increased. Parfenov [82] obtained the plasma by increasing the voltage in a traditional electrolysis process to oxidize the stainless steel and achieve the damage-free removal at the atomic level of the material. The highest MRR was $160 \mu \mathrm{m} / \mathrm{h}$. After EPP processing for $15 \mathrm{~min}$, the stainless steel surface had a mirror finish, and the surface roughness was decreased from $0.5 \mu \mathrm{m}$ to $0.08 \mu \mathrm{m}$. Danilov [74] discussed the theoretical basis of EPP and carried out EPP on the 304 stainless steel, whose initial surface roughness Ra was $0.08 \mu \mathrm{m}$. A smooth surface $\mathrm{Ra}=0.023 \mu \mathrm{m}$ was obtained after $5 \mathrm{~min}$. Zeidler [83] conducted the EPP of stainless steel medical devices to reach an Ra of less than $0.02 \mu \mathrm{m}$. With the increase in voltage, the MRR could be increased by 10 times with a value of $300 \mu \mathrm{m} / \mathrm{h}$. The processing range of EPP was analyzed by Nestler [73]. According to the mechanism, EPP was only applicable to the conductive material, and it was mainly applied to polish stainless steel at present. The possibility of EPP for copper, copper alloy, and titanium alloy was discussed. The brass workpieces processed by EPP could achieve the same gloss in only 1/8 time of electrochemical polishing. Ablyaz [84] found that the surface quality of the EDM-processed workpiece could be effectively improved by EPP. Valiev [85] used the plasma of a glow discharge to polish and deburr the connection terminal of copper. The polishing speed was 2.5 times higher than that of electrolytic polishing.

Cornelsen [86] studied the electrolyte plasma polishing of the inner surface of the stainless steel pipe. Results showed that the average surface roughness Sa of the inner surface of the pipe decreased from $0.719 \mu \mathrm{m}$ to $0.030 \mu \mathrm{m}$ after polishing for $25 \mathrm{~s}$. Electrolyte plasma polishing was conducted to polish the nitrided steel by Kusmanov [87], and the experimental results showed that plasma polishing for 2 min could reduce the surface 
roughness of nitrided steel from $4.5 \mu \mathrm{m}$ to $1.9 \mu \mathrm{m}$ without changing the structure of the nitride layer.

$\mathrm{Li}$ [88] applied electrolyte plasma and ultrasonic vibration to the grinding of titanium alloy. The normal grinding force, tangential grinding force, and workpiece surface roughness of this technology were the lowest at a plasma voltage of $100 \mathrm{~V}$, which were reduced by $60 \%, 70 \%$, and $46 \%$, respectively, compared with that of the conventional grinding. The addition of plasma made the workpiece surface produce a layer of oxide whose hardness was much less than that of the substrate, which reduced the grinding force, while ultrasonic vibration promoted the plasma oxidation effect on the workpiece surface.

Electrolyte plasma was successfully applied to the precision polishing of single-crystal $\mathrm{SiC}$ in our previous research. Experimental results showed that the MRR can be greatly improved with low surface roughness by a combination of plasma electrolytic processing and mechanical polishing for single-crystal $4 \mathrm{H}-\mathrm{SiC}[89,90]$. Ultrasonic-assisted polishing could improve the polishing efficiency and quality. A study by Li [88] also proved that the plasma oxidation effect on the workpiece surface can be promoted by the ultrasonic vibration. Therefore, ultrasonic-assisted electrolyte plasma polishing of single-crystal SiC may be an effective way to greatly improve the MRR and surface quality.

\section{Conclusions}

In this paper, single-crystal $\mathrm{SiC}$ precision polishing technologies, such as CMP, PCMP, PAP, ECMP, and CARE, were reviewed and compared with emphasis on the experimental setup, polishing mechanism, MRR, and surface roughness. Ultrasonic vibration-assisted single-crystal $\mathrm{SiC}$ polishing and EPP were discussed. Furthermore, the research direction for further improving the surface quality and MRR of single-crystal $\mathrm{SiC}$ was prospected. Conclusions can be drawn as below:

(1) The mechanism of CMP, PCMP, PAP, and ECMP was that the surface of single-crystal $\mathrm{SiC}$ was modified into a lower-hardness oxide layer $\left(\mathrm{SiO}_{2}\right.$ and silicon oxycarbide) compared with the substrate, which was mechanically removed by the soft abrasive particles. CARE is a polishing technique that uses a metal catalyst to accelerate the chemical dissolution of single-crystal $\mathrm{SiC}$ in the absence of abrasive conditions, while the metal is used as a polishing disc to smooth-polish single-crystal SiC.

(2) In the oxide layer, $\mathrm{SiO}_{2}$ was located at the top layer, and silicon oxycarbide, whose hardness was greater than that of $\mathrm{SiO}_{2}$ and less than that of $\mathrm{SiC}$, was located at the interface between the oxide layer and $\mathrm{SiC}$.

(3) The MRR and surface quality were a coupled result of the surface oxidation and mechanical removal of single-crystal SiC. The balance between the oxide layer's mechanical removal rate and the formation rate was necessary to obtain a smooth surface without defects.

(4) The surface roughness after PAP and CARE was the smallest, while the MRR of ECMP was the highest. CMP is still the common precision polishing technology for single-crystal $\mathrm{SiC}$ in industrial production with comprehensive consideration of the experimental setup, the MRR, and the surface roughness.

(5) Ultrasonic-assisted electrolyte plasma polishing of single-crystal SiC may be the future research direction that can be an effective way to greatly improve the MRR and surface quality.

Author Contributions: Conceptualization, methodology, investigation, writing-original draft preparation, G.M.; conceptualization, writing - review and editing, funding acquisition, project administration, S.L.; software, visualization, data curation, F.L. and C.Z.; software, data curation, Z.J. and X.Y. All authors have read and agreed to the published version of the manuscript.

Funding: This work is supported by the National Natural Science Foundation of China (No. 51575442) and Shaanxi Provincial Natural Science Foundation (2016JZ011).

Conflicts of Interest: The authors declare no conflict of interest. 


\section{References}

1. Madar, R. Silicon carbide in contention. Nature 2004, 430, 974-975. [CrossRef] [PubMed]

2. Dzurak, A. Diamond and silicon converge. Nature 2011, 479, 47-48. [CrossRef]

3. Reis, F.; Li, G.; Dudy, L.; Bauernfeind, M.; Glass, S.; Hanke, W.; Thomale, R.; Schäfer, J.; Claessen, R. Bismuthene on a SiC substrate: A candidate for a high-temperature quantum spin Hall material. Science 2017, 357, 287-290. [CrossRef]

4. Ruddy, F.H.; Seidel, J.G.; Haoqian, C.; Dulloo, A.R.; Sei-Hyung, R. High-resolution alpha-particle spectrometry using 4H silicon carbide semiconductor detectors. IEEE Trans. Nucl. Sci. 2006, 53, 1713-1718. [CrossRef]

5. Puglisi, D.; Bertuccio, G. Silicon Carbide Microstrip Radiation Detectors. Micromachines 2019, 10, 835. [CrossRef]

6. Kleppinger, J.W.; Chaudhuri, S.K.; Karadavut, O.; Mandal, K.C. Defect characterization and charge transport measurements in high-resolution $\mathrm{Ni} / \mathrm{n}-4 \mathrm{H}-\mathrm{SiC}$ Schottky barrier radiation detectors fabricated on $250 \mu \mathrm{m}$ epitaxial layers. J. Appl. Phys. 2021, 129, 244501. [CrossRef]

7. Chaudhuri, S.K.; Mandal, K.C. Radiation detection using n-type 4H-SiC Epitaxial Layer Surface Barrier Detectors. In Advanced Materials for Radiation Detection; Spring: Berlin/Heidelberg, Germany, 2021; pp. 183-209.

8. Ohmi, T.; Miyashita, M.; Itano, M.; Imaoka, T.; Kawanabe, I. Dependence of thin-Oxide films quality on surface microroughness. IEEE Trans. Electron Devices 1922, 39, 537-545. [CrossRef]

9. Grim, J.R.; Benamara, M.; Skowronski, M.; Everson, W.J.; Heydemann, V.D. Transmission electron microscopy analysis of mechanical polishing-related damage in silicon carbide wafers. Semicond. Sci. Technol. 2006, 21, 1709-1713. [CrossRef]

10. Guoshun, P.; Yan, Z.; Guihai, L.; Xiaolei, S.; Chunli, Z.; Hua, G. Chemical mechanical polishing (CMP) of on-axis Si-face 6H-SiC wafer for obtaining atomically flat defect-free surface. J. Mater. Sci. Mater. Electron. 2013, 24, 5040-5047. [CrossRef]

11. Guomei, C.; Zifeng, N.; Yawen, B.; Qingzhong, L.; Yongwu, Z. The role of interactions between abrasive particles and the substrate surface in chemical-mechanical planarization of Si-face 6H-SiC. RSC Adv. 2017, 7, 16938-16952. [CrossRef]

12. Yamamura, K.; Takiguchi, T.; Ueda, M.; Hattori, A.N.; Zettsu, N. High-Integrity Finishing of 4H-SiC (0001) by Plasma-Assisted Polishing. Adv. Mater. Res. 2010, 126-128, 423-428. [CrossRef]

13. Jia, G.; Li, B.; Zhang, J. Influence of SiC surface defects on materials removal in atmospheric pressure plasma polishing. Comput. Mater. Sci. 2018, 146, 26-35. [CrossRef]

14. Zewei, Y.; Yan, H.; Xingwei, S.; Quan, W. UV-TiO2 photocatalysis-assisted chemical mechanical polishing 4H-SiC wafer. Mater. Manuf. Processes 2017, 33, 1214-1222. [CrossRef]

15. Deng, H.; Hosoya, K.; Imanishi, Y.; Endo, K.; Yamamura, K. Electro-chemical mechanical polishing of single-crystal SiC using $\mathrm{CeO}_{2}$ slurry. Electrochem. Commun. 2015, 52, 5-8. [CrossRef]

16. Yang, X.; Yang, X.; Kawai, K.; Arima, K.; Yamamura, K. Highly efficient planarization of sliced 4H-SiC (0001) wafer by slurryless electrochemical mechanical polishing. Int. J. Mach. Tools Manuf. 2019, 144, 103431. [CrossRef]

17. Hara, H.; Sano, Y.; Mimura, H.; Arima, K.; Kubota, A.; Yagi, K.; Murata, J.; Yamauch, K. Novel abrasive-free planarization of 4H-SiC (0001) using catalyst. J. Electron. Mater. 2006, 35, L11-L14. [CrossRef]

18. Kenta, A.; Hideyuki, H.; Junji, M.; Takeshi, I.; Ryota, O.; Keita, Y.; Yasuhisa, S.; Hidekazu, M.; Kazuto, Y. Atomic-scale flattening of $\mathrm{SiC}$ surfaces by electroless chemical etching in HF solution with Pt catalyst. Appl. Phys. Lett. 2007, 90, 202106. [CrossRef]

19. van Dorp, D.H.; Sattler, J.J.H.B.; den Otter, J.H.; Kelly, J.J. Electrochemistry of anodic etching of $4 \mathrm{H}$ and $6 \mathrm{H}-\mathrm{SiC}$ in fluoride solution of pH 3. Electrochim. Acta 2009, 54, 6269-6275. [CrossRef]

20. Luo, H.; Ajmal, K.M.; Liu, W.; Yamamura, K.; Deng, H. Polishing and planarization of single crystal diamonds: State-of-the-art and perspectives. Int. J. Extrem. Manuf. 2021, 3, 022003. [CrossRef]

21. Luo, Q.F.; Lu, J.; Xu, X.P. A comparative study on the material removal mechanisms of $6 \mathrm{H}-\mathrm{SiC}$ polished by semi-fixed and fixed diamond abrasive tools. Wear 2016, 350-351, 99-106. [CrossRef]

22. Zhou, L.; Audurier, V.; Pirouz, P.; Powell, J.A. Chemomechanical Polishing of Silicon Carbide. J. Electrochem. Soc. 1997, 144, L161-L163. [CrossRef]

23. Guomei, C.; Zifeng, N.; Laijun, X.; Qingzhong, L.; Yongwu, Z. Performance of colloidal silica and ceria based slurries on CMP of Si-face 6H-SiC substrates. Appl. Surf. Sci. 2015, 359, 664-668. [CrossRef]

24. Neslen, C.L.; Mitchel, W.C.; Hengehold, R.L. Effects of process parameter variations on the removal rate in chemical mechanical polishing of $4 \mathrm{H}-\mathrm{SiC}$. J. Electron. Mater. 2001, 30, 1271-1275. [CrossRef]

25. Lee, H.S.; Jeong, H.D. Chemical and mechanical balance in polishing of electronic materials for defect-free surfaces. CIRP Ann. Manuf. Technol. 2009, 58, 485-490. [CrossRef]

26. Lee, H.S.; Kim, D.I.; An, J.H.; Lee, H.J.; Kim, K.H.; Jeong, H. Hybrid polishing mechanism of single crystal SiC using mixed abrasive slurry (MAS). CIRP Ann. Manuf. Technol. 2010, 59, 333-336. [CrossRef]

27. Heydemann, V.D.; Everson, W.J.; Gamble, R.D.; Snyder, D.; Skowronski, M. Chemi-mechanical polishing of on-Axis semiinsulating SiC substrates. Mater. Sci. Forum 2004, 457-460, 805-808. [CrossRef]

28. Ho, A.J.; Sub, L.G.; Jae, L.W.; Chul, S.B.; Doo, S.J.; Ryeol, K.K.; Seo, H.D.; Jeong, H.D. Effect of Process Parameters on Material Removal Rate in Chemical Mechanical Polishing of 6H-SiC(0001). Mater. Sci. Forum 2008, 600-603, 831-834. [CrossRef]

29. Yan, Z.; Guoshun, P.; Xiaolei, S.; Li, X.; Chunli, Z.; Hua, G.; Guihai, L. XPS, UV-vis spectroscopy and AFM studies on removal mechanisms of Si-face SiC wafer chemical mechanical polishing (CMP). Appl. Surf. Sci. 2014, 316, 643-648. [CrossRef]

30. Hoshino, T.; Kurata, Y.; Terasaki, Y.; Susa, K. Mechanism of polishing of $\mathrm{SiO}_{2}$ films by $\mathrm{CeO}_{2}$ particles. J. Non Cryst. Solids 2001, 283, 129-136. [CrossRef] 
31. Tsai, M.Y.; Wang, S.M.; Tsai, C.C.; Yeh, T.S. Investigation of increased removal rate during polishing of single-crystal silicon carbide. Int. J. Adv. Manuf. Technol. 2015, 80, 1511-1520. [CrossRef]

32. Hu, C.Y.; Lo, S.L.; Li, C.M.; Kuan, W.H. Treating chemical mechanical polishing (CMP) wastewater by electro-coagulation-flotation process with surfactant. J. Hazard Mater 2005, 120, 15-20. [CrossRef] [PubMed]

33. Chou, W.L.; Wang, C.T.; Chang, W.C.; Chang, S.Y. Adsorption treatment of oxide chemical mechanical polishing wastewater from a semiconductor manufacturing plant by electrocoagulation. J. Hazard Mater 2010, 180, 217-224. [CrossRef] [PubMed]

34. Ishikawa, Y.; Matsumoto, Y.; Nishida, Y.; Taniguchi, S.; Watanabeł, J. Surface treatment of silicon carbide using TiO $2(\mathrm{IV})$ photocatalyst. J. Am. Chem. Soc. 2003, 125, 6558-6562. [CrossRef] [PubMed]

35. Osamu, O.; Toshiro, D.; Syuhei, K.; Tsutomu, Y.; Michio, U.; Tao, Y.; Isamu, K.; Koichiro, I.; Hideo, A. Effects of atmosphere and ultraviolet light irradiation on chemical mechanical polishing characteristics of SiC wafers. Jpn. J. Appl. Phys. 2012, 51, $05 E F 05$. [CrossRef]

36. Jing, L.; Yaguang, W.; Qiufa, L.; Xipeng, X. Photocatalysis assisting the mechanical polishing of a single-crystal SiC wafer utilizing an anatase $\mathrm{TiO}_{2}$-coated diamond abrasive. Precis. Eng. 2017, 49, 235-242. [CrossRef]

37. Yamamura, K.; Takiguchi, T.; Ueda, M.; Deng, H.; Hattori, A.N.; Zettsu, N. Plasma assisted polishing of single crystal SiC for obtaining atomically flat strain-free surface. CIRP Ann. Manuf. Technol. 2011, 60, 571-574. [CrossRef]

38. Deng, H.; Takiguchi, T.; Ueda, M.; Hattori, A.N.; Zettsu, N.; Yamamura, K. Damage-free dry polishing of $4 \mathrm{H}-\mathrm{SiC}$ combined with atmospheric-pressure water vapor plasma oxidation. Jpn. J. Appl. Phys. 2011, 50, 08JG05. [CrossRef]

39. Deng, H.; Ueda, M.; Yamamura, K. Characterization of $4 \mathrm{H}-\mathrm{SiC}$ (0001) surface processed by plasma-assisted polishing. Int. J. Adv. Manuf. Technol. 2012, 72, 1-7. [CrossRef]

40. Deng, H.; Yamamura, K. XPS analysis of $4 \mathrm{H}-\mathrm{SiC}$ surfaces oxidized by helium-based atmospheric-pressure water vapor plasma for plasma-assisted polishing. Mater. Sci. Forum 2013, 740-742, 514-517. [CrossRef]

41. Deng, H.; Yamamura, K. Atomic-scale flattening mechanism of 4H-SiC (ll 0001$)$ in plasma assisted polishing. CIRP Ann. Manuf. Technol. 2013, 62, 575-578. [CrossRef]

42. Deng, H.; Endo, K.; Yamamura, K. Experimental Studies on Water Vapor Plasma Oxidation and Thermal Oxidation of 4H-SiC (0001) for Clarification of the Atomic-Scale Flattening Mechanism in Plasma Assisted Polishing. Mater. Sci. Forum 2014, 778-780, 587-590. [CrossRef]

43. Deng, H.; Endo, K.; Yamamura, K. Comparison of thermal oxidation and plasma oxidation of $4 \mathrm{H}-\mathrm{SiC}$ (0001) for surface flattening. Appl. Phys. Lett. 2014, 104, 101608. [CrossRef]

44. Deng, H.; Endo, K.; Yamamura, K. Damage-free and atomically-flat finishing of single crystal SiC by combination of oxidation and soft abrasive polishing. Procedia CIRP 2014, 13, 203-207. [CrossRef]

45. Deng, H.; Monna, K.; Tabata, T.; Endo, K.; Yamamura, K. Optimization of the plasma oxidation and abrasive polishing processes in Plasma assisted polishing for highly effective planarization of 4H-SiC. CIRP Ann. Manuf. Technol. 2014, 36, 529-532. [CrossRef]

46. Deng, H.; Endo, K.; Yamamura, K. Competition between surface modification and abrasive polishing: A method of controlling the surface atomic structure of $4 \mathrm{H}-\mathrm{SiC}$ (0001). Sci. Rep. 2015, 5, 1-6. [CrossRef]

47. Li, C.; Bhat, I.B.; Wang, R.; Seiler, J. Electro-chemical mechanical polishing of silicon carbide. J. Electron. Mater. 2004, 33, 481-486. [CrossRef]

48. Yamamura, K.; Hosoya, K.; Imanishi, Y.; Deng, H.; Endo, K. Preliminary study on highly efficient polishing of $4 \mathrm{H}-\mathrm{SiC}$ by utilization of anodic oxidation. Adv. Mater. Res. 2014, 1017, 509-514. [CrossRef]

49. Murata, J.; Yodogawa, K.; Ban, K. Polishing-pad-free electrochemical mechanical polishing of single-crystalline SiC surfaces using polyurethane-CeO2 core-shell particles. Int. J. Mach. Tools Manuf. 2017, 114, 1-7. [CrossRef]

50. Gao, B.; Zhai, W.J.; Zhai, Q.; Xia, Y.L.; Wang, C.; Peng, K.X. Electro-chemical mechanical polishing of $4 \mathrm{H}-\mathrm{SiC}$ for scratch-free surfaces with less oxide layer at high efficiency. ECS J. Solid State Sci. Technol. 2019, 8, P677-P684. [CrossRef]

51. Yang, X.; Yang, X.; Sun, R.; Kawai, K.; Arima, K.; Yamamura, K. Obtaining atomically smooth 4H-SiC (0001) surface by controlling balance between anodizing and polishing in electrochemical mechanical polishing. Nanomanuf. Metrol. 2019, 2, 140-147. [CrossRef]

52. Yang, X.; Sun, R.; Kawai, K.; Arima, K.; Yamamura, K. Surface modification and microstructuring of 4H-SiC(0001) by anodic oxidation with sodium chloride aqueous solution. ACS Appl. Mater. Interfaces 2019, 11, 2535-2542. [CrossRef]

53. Murata, J.; Nagatomo, D. Investigation of electrolytic condition on abrasive-free electrochemical mechanical polishing of $4 \mathrm{H}-\mathrm{SiC}$ using Ce thin film. ECS J. Solid State Sci. Technol. 2020, 9, 034002. [CrossRef]

54. Deng, H.; Liu, N.; Endo, K.; Yamamura, K. Atomic-scale finishing of carbon face of single crystal SiC by combination of thermal oxidation pretreatment and slurry polishing. Appl. Surf. Sci. 2018, 434, 40-48. [CrossRef]

55. Liu, N.; Yi, R.; Deng, H. Study of initiation and development of local oxidation phenomena during anodizing of SiC. Electrochem. Commun. 2018, 89, 27-31. [CrossRef]

56. Yang, X.; Ohkubo, Y.; Endo, K.; Yamamura, K. AFM observation of initial oxidation stage of 4H-SiC (0001) in electrochemical mechanical polishing. Procedia CIRP 2018, 68, 735-740. [CrossRef]

57. Yang, X.; Sun, R.; Ohkubo, Y.; Kawai, K.; Arima, K.; Endo, K.; Yamamura, K. Investigation of anodic oxidation mechanism of $4 \mathrm{H}-\mathrm{SiC}$ (0001) for electrochemical mechanical polishing. Electrochim. Acta 2018, 271, 666-676. [CrossRef] 
58. Okamoto, T.; Sano, Y.; Tachibana, K.; Pho, B.V.; Arima, K.; Inagaki, K.; Yagi, K.; Murata, J.; Sadakuni, S.; Asano, H.; et al. Improvement of Removal Rate in Abrasive-Free Planarization of $4 \mathrm{H}-\mathrm{SiC}$ Substrates Using Catalytic Platinum and Hydrofluoric Acid. Jpn. J. Appl. Phys. 2012, 51, 046501. [CrossRef]

59. Sano, Y.; Arima, K.; Yamauchi, K. Planarization of SiC and GaN Wafers Using Polishing Technique Utilizing Catalyst Surface Reaction. ECS J. Solid State Sci. Technol. 2013, 2, N3028-N3035. [CrossRef]

60. Lsohashi, A.; Sano, Y.; Okamoto, T.; Tachibana, K.; Arima, K.; Lnagaki, K.; Yagi, K.; Sadakuni, S.; Morikawa, Y.; Yamauchi, K. Study on Reactive Species in Catalyst-Referred Etching of 4H-SiC using Platinum and Hydrofluoric Acid. Mater. Sci. Forum 2013, 740-742, 847-850. [CrossRef]

61. Yagi, K.; Murata, J.; Kubota, A.; Sano, Y.; Hara, H.; Okamoto, T.; Arima, K.; Mimura, H.; Yamauchi, K. Catalyst-referred etching of $4 \mathrm{H}-\mathrm{SiC}$ substrate utilizing hydroxyl radicals generated from hydrogen peroxide molecules. Surf. Interface Anal. 2008, 40, 998-1001. [CrossRef]

62. Kubota, A.; Yagi, K.; Murata, J.; Yasui, H.; Miyamoto, S.; Hara, H.; Sano, Y.; Yamauchi, K. A Study on a Surface Preparation Method for Single-Crystal SiC Using an Fe Catalyst. J. Electron. Mater. 2008, 38, 159-163. [CrossRef]

63. Isohashi, A.; Bui, P.V.; Toh, D.; Matsuyama, S.; Sano, Y.; Inagaki, K.; Morikawa, Y.; Yamauchi, K. Chemical etching of silicon carbide in pure water by using platinum catalyst. Appl. Phys. Lett. 2017, 110, 201601. [CrossRef]

64. Van Bui, P.; Toh, D.; Isohashi, A.; Matsuyama, S.; Inagaki, K.; Sano, Y.; Yamauchi, K.; Morikawa, Y. Platinum-catalyzed hydrolysis etching of $\mathrm{SiC}$ in water: A density functional theory study. Jpn. J. Appl. Phys. 2018, 57, 055703. [CrossRef]

65. Okamoto, T.; Sano, Y.; Hara, H.; Hatayama, T.; Arima, K.; Yagi, K.; Murata, J.; Sadakuni, S.; Tachibana, K.; Shirasawa, Y.; et al. Reduction of Surface Roughness of $4 \mathrm{H}-\mathrm{SiC}$ by Catalyst-Referred Etching. Mater. Sci. Forum 2010, 645-648, 775-778. [CrossRef]

66. Yan, Z.; Guoshun, P.; Xiaolei, S.; Hua, G.; Guihai, L.; Zhonghua, G. Chemical mechanical planarization (CMP) of on-axis Si-face $\mathrm{SiC}$ wafer using catalyst nanoparticles in slurry. Surf. Coat. Technol. 2014, 251, 48-55. [CrossRef]

67. Zhao, Q.; Sun, Z.; Guo, B. Material removal mechanism in ultrasonic vibration assisted polishing of micro cylindrical surface on SiC. Int. J. Mach. Tools Manuf. 2016, 103, 28-39. [CrossRef]

68. Hu, Y.; Shi, D.; Hu, Y.; Zhao, H.; Sun, X. Investigation on the material removal and surface generation of a single crystal SiC wafer by ultrasonic chemical mechanical polishing combined with ultrasonic lapping. Materials 2018, 11, 2022. [CrossRef] [PubMed]

69. Yang, X.; Yang, X.; Kawai, K.; Arima, K.; Yamamura, K. Ultrasonic-assisted anodic oxidation of 4H-SiC (0001) surface. Electrochem. Commun. 2019, 100, 1-5. [CrossRef]

70. Ashokkumar, M.; Sunartio, D.; Kentish, S.; Mawson, R.; Simons, L.; Vilkhu, K.; Versteeg, C. Modification of food ingredients by ultrasound to improve functionality: A preliminary study on a model system. Innov. Food Sci. Emerg. Technol. 2008, 9, 155-160. [CrossRef]

71. Makino, K.; Mossoba, M.M.; Riesz, P. Chemical effects of ultrasound on aqueous solutions. Formation of hydroxyl radicals and hydrogen atoms. J. Phys. Chem. 1983, 87, 1369-1377. [CrossRef]

72. Han, W.; Fang, F. Fundamental aspects and recent developments in electropolishing. Int. J. Mach. Tools Manuf. 2019, 139, 1-23. [CrossRef]

73. Nestler, K.; Böttger-Hiller, F.; Adamitzki, W.; Glowa, G.; Zeidler, H.; Schubert, A. Plasma electrolytic polishing-An Overview of applied technologies and current challenges to extend the polishable material range. Procedia CIRP 2016, 42, 503-507. [CrossRef]

74. Danilov, I.; Hackert-Oschatzchen, M.; Zinecker, M.; Meichsner, G.; Edelmann, J.; Schubert, A. Process understanding of plasma electrolytic polishing through multiphysics simulation and inline metrology. Micromachines 2019, 10, 214. [CrossRef] [PubMed]

75. Kellogg, H.H. Anode Effect in Aqueous Electrolysis. J. Electrochem. Soc. 1950, 97, 133-142. [CrossRef]

76. Kalenchukova, V.O.; Nagula, P.K.; Tretinnikov, D.L. About changes in the chemical composition of the electrolyte in the process of electrolytic-plasma treatment of materials. Mater. Methods Technol. 2015, 9, 404-413.

77. Vana, D.; Podhorsky, S.; Hurajt, M.; Hanzen, V. Surface Properties of the Stainless Steel X10 CrNi 18/10 after Aplication of Plasma Polishing in Electrolyte. Int. J. Mod. Eng. Res. 2013, 3, 788-792.

78. Wang, J.; Suo, L.C.; Guan, L.L.; Fu, Y.L. Analytical study on mechanism of electrolysis and plasma polishing. Adv. Mater. Res. 2012, 472-475, 350-353. [CrossRef]

79. Cornelsen, M.; Deutsch, C.; Seitz, H. Electrolytic plasma polishing of pipe inner surfaces. Metals 2018, 8, 12. [CrossRef]

80. Clements, J.S.; Sato, M.; Davis, R.H. Preliminary Investigation of Prebreakdown Phenomena and Chemical Reactions Using a Pulsed High-Voltage Discharge in Water. IEEE Trans. Ind. Appl. 1987, 24, 224-235. [CrossRef]

81. Sun, B.; Kunitomo, S.; Igarashi, C. Characteristics of ultraviolet light and radicals formed by pulsed discharge in water. J. Phys. D Appl. Phys. 2006, 39, 3814-3820. [CrossRef]

82. Parfenov, E.V.; Farrakhov, R.G.; Mukaeva, V.R.; Gusarov, A.V.; Nevyantseva, R.R.; Yerokhin, A. Electric field effect on surface layer removal during electrolytic plasma polishing. Surf. Coat. Technol. 2016, 307, 1329-1340. [CrossRef]

83. Zeidler, H.; Boettger-Hiller, F.; Edelmann, J.; Schubert, A. Surface finish machining of medical parts using plasma electrolytic polishing. Procedia CIRP 2016, 49, 83-87. [CrossRef]

84. Ablyaz, T.R.; Muratov, K.R.; Ushomirskaya, L.A.; Zarubin, D.A.; Sidhu, S.S. Electrolytic plasma polishing technique for improved surface finish of ED machined components. Eng. Solid Mech. 2019, 7, 131-136. [CrossRef]

85. Valiev, R.I.; Khafizov, A.A.; Shakirov, Y.I.; Sushchikova, A.N. Polishing and deburring of machine parts in plasma of glow discharge between solid and liquid electrodes. IOP Conf. Ser. Mater. Sci. Eng. 2015, 86, 012026. [CrossRef] 
86. Cornelsen, M.; Deutsch, C.; Seitz, H. Influence of the Velocity and the Number of Polishing Passages on the Roughness of Electrolytic Plasma Polished Pipe Inner Surfaces. Metals 2018, 8, 330. [CrossRef]

87. Kusmanov, S.; Zhirov, A.; Kusmanova, I.; Belkin, P. Aspects of anodic plasma electrolytic polishing of nitrided steel. Surf. Eng. 2017, 35, 507-511. [CrossRef]

88. Li, S.; Wu, Y.; Yamamura, K.; Nomura, M.; Fujii, T. Improving the grindability of titanium alloy Ti-6Al-4V with the assistance of ultrasonic vibration and plasma electrolytic oxidation. CIRP Ann. Manuf. Technol. 2017, 66, 345-348. [CrossRef]

89. Ma, G.; Li, S.; Liu, X.; Yin, X.; Jia, Z.; Liu, F. Combination of Plasma Electrolytic Processing and Mechanical Polishing for Single-Crystal 4H-SiC. Micromachines 2021, 12, 606. [CrossRef] [PubMed]

90. Yin, X.; Li, S.; Ma, G.; Jia, Z.; Liu, X. Investigation of oxidation mechanism of SiC single crystal for plasma electrochemical oxidation. RSC Adv. 2021, 11, 27338-27345. [CrossRef] 